\title{
Timeless couples G quadruplex detection with processing by DDX11 during DNA replication
}

Leticia Koch Lerner $^{1 \&}$, Sandro Holzer ${ }^{2 \&}$, Mairi L. Kilkenny ${ }^{2}$, Pierre Murat ${ }^{1}$, Saša Švikovićc Davide Schiavone ${ }^{1}$, Alice Bittleston ${ }^{2}$, Joseph D. Maman ${ }^{2}$, Dana Branzei ${ }^{3}$, Katherine Stott ${ }^{2}$, Luca Pellegrini $^{2 *}$ and Julian E. Sale ${ }^{1^{*}}$

${ }^{1}$ MRC Laboratory of Molecular Biology, Francis Crick Avenue, Cambridge, CB2 0QH, UK

${ }^{2}$ Department of Biochemistry, University of Cambridge, Cambridge, CB2 1GA, UK

${ }^{3}$ IFOM, Fondazione Italiana per la Ricerca sul Cancro, Institute of Molecular Oncology, Milan, 20139, Italy

* to whom correspondence should be addressed: jes@mrc-lmb.cam.ac.uk or 1p212@cam.ac.uk $\&$ equal contribution 
Regions of the genome with the potential to form secondary structure pose a frequent and significant impediment to DNA replication and must be actively managed in order to preserve genetic and epigenetic integrity. The fork protection complex (FPC), a conserved group of replisome-associated proteins including Timeless, Tipin, and Claspin, plays an important role in maintaining efficient replisome activation, ensuring optimum fork rates, sister chromatid cohesion and checkpoint function. It also helps maintain the stability of sequences prone to secondary structure formation through an incompletely understood mechanism. Here, we report a previously unappreciated DNA binding domain in the C-terminus of Timeless, which exhibits specific binding to $G$ quadruplex (G4) structures. We show that, in vivo, both the C-terminus of Timeless and the DDX11 helicase act collaboratively to ensure processive replication of G4 structures to prevent genetic and epigenetic instability.

DNA can create significant impediments to its own replication through formation of secondary structures. When unwound, certain sequences, often repetitive or of low complexity, can adopt a variety of non-B form structures, including hairpins, cruciforms, triplexes and quadruplexes ${ }^{1}$. It is becoming clear that secondary structure formation is a frequent event during replication, even at genomically abundant sequences previously thought not to be a major source of difficulty ${ }^{2}$. To prevent such sequences causing havoc with the genetic and epigenetic stability of the genome, cells deploy an intricate network of activities to counteract secondary structure formation and limit its effects. These activities include proteins that bind and destabilise DNA structures and specialised helicases that unwind them ${ }^{3}$. In addition, the repriming activity of PrimPol can be deployed to confine a structure into a minimal region of single stranded DNA, limiting the potential dangers of exposing extensive ssDNA in a stalled replisome ${ }^{2,4}$.

G quadruplexes (G4s) are one of the most intensively studied and potent structural replication impediments. G4s arise in consequence of the ability of guanine to form Hoogsteen base-paired quartets ${ }^{5}$. In favourable sequence contexts, comprising runs of $\mathrm{dG}$ separated by variable numbers of non-G bases, stacks of $\mathrm{G}$ quartets form G4s secondary structures. Current estimates suggest that over 700,000 sites in the human genome have the potential to form $\mathrm{G} 4 \mathrm{~s}^{6}$. While some of these G4s may have important roles in genome physiology, all pose a potential threat to DNA replication and sites with G4-forming potential have been linked to both genetic and epigenetic instability ${ }^{7,8}$. 
Precisely how DNA structures are detected and resolved by the replication machinery remains unclear. Many of the factors involved in processing G4 secondary structures, for instance FANCJ and REV1 ${ }^{9-13}$, do not appear to be constitutive components of the replisome ${ }^{14}$. It is thus likely that core components of the replisome will act as 'first responders' to DNA structures and play an important role coupling their detection with suppressing their deleterious effects on DNA synthesis. Particularly interesting in this context is a subset of replisome components known as the fork protection complex (FPC). The FPC comprises four main proteins, Timeless, Tipin, Claspin and And-1 and is conserved from yeast to mammals ${ }^{15}$. FPC components associate with the replication fork via direct interactions with the CMG replicative helicase and replicative polymerases $\alpha, \delta$ and $\varepsilon^{16-19}$. They also interact with DNA both directly ${ }^{20}$ and indirectly via replication protein $\mathrm{A}^{21}$. These interactions allow the FPC to remain at the fork, which ensures a normal speed of DNA synthesis ${ }^{22}$. Additionally, the FPC has a series of functions that ensure normal replisome function and fork integrity: it is essential to avoid uncoupling of pol $\varepsilon$ from the replicative helicase and consequent formation of long stretches of ssDNA ${ }^{23,24}$. It also has a conserved role in S-phase checkpoint activation in response to DNA damage, including checkpoint kinase activation, cell cycle arrest and maintenance of the integrity of the replication fork ${ }^{25-28}$. It also plays an important, but incompletely understood, role in maintaining chromosome cohesion ${ }^{29,30}$.

The FPC is thus well placed to play a role in the detection and metabolism of DNA secondary structures that could impede DNA synthesis. Indeed, deficiency of both Tof1 in yeast and Timeless in human cells leads to replication fork stalling, repeat instability and fragility at secondary structure-forming sequences ${ }^{31-35}$, underscoring the potential importance of Timeless in maintaining processive replication through regions of the genome capable of forming secondary structures.

Although Timeless itself does not appear to possess a catalytic activity that would process DNA secondary structures, it interacts with the helicase DDX11 ${ }^{36}$. DDX11 (or CHLR1) is a 5'-3' Fe-S helicase and belongs to the same superfamily 2 as FANCJ, RTEL and XPD ${ }^{3}$. In humans, mutations in DDX11 cause Warsaw Breakage Syndrome, an extremely rare autosomal recessive disease characterised by microcephaly, growth retardation, cochlear abnormalities and abnormal skin pigmentation ${ }^{37}$. In vitro, DDX11 has unwinding activity on several nonduplex DNA structures, such as G4s ${ }^{38,39}$, triplex DNA ${ }^{40}$ and D-loops ${ }^{39}$. Further, the helicase activity of DDX11 is enhanced by Timeless ${ }^{36}$. However, it remains unclear how Timeless and 
DDX11 collaborate in vivo in detecting and processing G4s during replication. Here, we provide in vivo evidence that Timeless and DDX11 operate together to ensure processive replication of G4-forming DNA. We report a previously unappreciated DNA binding domain in the C-terminus of Timeless, which exhibits specificity towards G4 structures. We propose that the C-terminus of Timeless plays a role in the detection of G4 structures at the replication fork, recruiting DDX11 to unwind them to ensure processive replication is maintained, thereby avoiding G4-induced genetic and epigenetic stability.

\section{Results}

\section{Timeless is required for processive replication of a genomic G4-motif}

To address whether Timeless is involved in maintaining processive replication of G4-forming DNA in vivo, we disrupted the TIMELESS locus in chicken DT40 cells with CRISPR/Cas9induced deletions. We isolated several timeless mutants with biallelic disruptions in exon 1, around the guide site (Supplementary Fig. 1). The timeless mutant cells were sensitive to cisplatin (Supplementary Fig. 2), as previously observed in human cells depleted of Timeless 41. To assess the role of Timeless in the replication of a G4-forming sequence, we took advantage of the $\mathrm{Bu}-1$ loss variant assay ${ }^{42}$. The stable expression of the $B U-1$ locus in DT40 is dependent on the maintenance of processive replication through a G4 motif located approximately $3.5 \mathrm{~kb}$ downstream of the promoter (Fig. 1a). Prolonged pausing of leading strand replication at this motif leads to loss of epigenetic information around the promoter of the gene and a permanent and heritable change in its expression ${ }^{4,42-44}$. This stochastic and replication-dependent generation of $\mathrm{Bu}-1$ loss variants can be monitored by flow cytometry as $B U-1$ encodes a surface glycoprotein. Small pools of $\mathrm{Bu}-1^{\text {high }}$ cells of wild type and timeless mutants were expanded in parallel for $\sim 20$ divisions ( $15-21$ days) and the proportion of cells in each pool that had lost their $\mathrm{Bu}-1^{\text {high }}$ status determined. We detected increased levels of $\mathrm{Bu}-$ 1 expression instability in timeless DT40 cells compared to the wild-type cells, which retained their stable $\mathrm{Bu}-1^{\text {high }}$ expression (Fig. $1 \mathrm{~b} \& \mathrm{c}$ ). The instability of $\mathrm{Bu}-1$ expression in timeless cells was fully complemented by expression of human Timeless (Fig. 1c) and is dependent on the +3.5 G4 motif (Fig. 1c). Cells deficient in Tipin ${ }^{45}$, a constitutive interactor of Timeless within the FPC, also exhibit instability of $B U-1$ expression (Fig. 1d). These results show that Timeless is necessary to maintain processive DNA replication of a genomic G4-motif. 


\section{Identification and characterisation of a Timeless DNA-binding domain}

As a core component of the replisome, Timeless is intimately associated with DNA synthesis at the replication fork ${ }^{22}$. In vitro data show that the Timeless-Tipin complex can bind to singlestranded DNA (ssDNA) through RPA ${ }^{21}$ and the Swil-Swi3 complex, the fission yeast orthologue of Timeless-Tipin, was also shown to bind DNA ${ }^{20}$. Inspection of the amino acid sequence of human Timeless revealed the presence of a conserved domain in its C-terminal half (residue 816 to 954) (Fig. 2a), with a predicted fold similarity to the myb-like proteins of the homeodomain-like superfamily, that bind double-stranded DNA (dsDNA) with a tandem repeat of 3-helix bundles (named here $\mathrm{N}$-term and $\mathrm{C}$-term).

We used X-ray diffraction and NMR spectroscopy to investigate experimentally the structure and dynamics of the newly discovered Timeless domain. The $1.15 \AA$ crystal structure of amino acids 885 to 947 (C-term), corresponding to a single myb-like fold, confirmed the presence of a three-helix bundle characteristic of the homeodomain superfamily of DNA-binding proteins, extended by the presence of a fourth C-terminal alpha helix unique to the Timeless domain (Fig. 2b). The NMR structural ensemble of amino acids 816 to 954 revealed two wellconverged domains (824-880 and 891-944, backbone r.m.s.d. 0.4 and $0.5 \AA$, respectively) connected by a linker (881-890) that was significantly less well converged, implying a high degree of flexibility between $\mathrm{N}$ - and C-term domains (Fig. 2c). This observation was confirmed by backbone dynamics measurements (Supplementary Fig. 3). The N- and C-terminal domains adopted the same three-dimensional fold; in particular, the N-terminal repeat shared the presence of an additional fourth helix, H4, as seen in the C-terminal repeat (Fig. 2c).

In keeping with the similarity of its structure to known DNA-binding domains, we examined the ability of the Timeless domain to interact with DNA. We found that it bound with low micromolar affinity to both ss- and ds-DNA probes (Fig. 2d; top panel). A distinguishing feature of the Timeless DNA-Binding Domain (DBD) is the presence of a fourth alpha helix in both $\mathrm{N}$ - and C-terminal 3-helix bundle repeats. Superposition of the DBD C-term onto the structurally homologous domains of the telomeric protein TRF1 ${ }^{46}$ and bacterial cell-cycle regulator GcrA ${ }^{47}$ in complex with their double-stranded DNA substrates (Fig. 2e) shows that, if the DBD were to adopt a similar model of dsDNA binding, the fourth helix of both its Nterm and C-term repeats would likely lead to a steric clash with the phosphate backbone of the DNA. 
Although it is conceivable that the DBD might rearrange its conformation upon DNA binding, the fourth helix of both repeats participates in core hydrophobic interactions, mediated by conserved residues L872 and F879 (N-terminal repeat), and L936, V937 and L943 (C-terminal repeat), making such rearrangements unlikely. Given the functional context in which Timeless operates as a replisome component and the observations, presented in Fig. 1, that it is required to maintain processive replication of the $B U-1$ G4, we speculated that the C-terminal DNAbinding activity of Timeless might be directed towards recognition of DNA secondary structures that form transiently on the unwound template, such as G4s.

Indeed, when we tested a well-characterised G4 sequence present in the promoter of the MYC gene ${ }^{48}$, the DBD bound to it with nanomolar affinity (Fig. $2 \mathrm{~d}$, bottom panel), and about one order of magnitude tighter than ds- or ssDNA. This observation prompted us to ask whether the Timeless-Tipin complex, like the isolated DBD, is able to bind to the same G4 motif. To mimic the unwound template DNA, we embedded the G4 within a longer ssDNA sequence (ssG4) (Supplementary Table 2). We found that the Timeless-Tipin complex bound to ssG4 with low micromolar affinity and in a selective fashion, as it did not show measurable interactions with a hairpin DNA embedded within the same ssDNA (ssHP), or a mutated ssG4 sequence that had lost the ability to fold into a guanine quadruplex (ss) (Fig. 3a, Supplementary Fig. 4, Supplementary Table 2). We next tested a series of G4 sequences, found in different genomic contests and with different folding topologies: we found that the Timeless-Tipin complex bound to all of them, albeit with different affinities that varied several fold, whereas it did not show appreciable binding to ss- or dsDNA (Fig. 3b).

These findings show that Timeless contains, in its C-terminal half, a previously unrecognised DNA-binding domain, which closely resembles in structure the tandem repeat of three-helix bundles found in the homeodomain-like superfamily of transcription factors. While Timeless DBD binds to both ss- and dsDNA, it binds with $\sim 10$-fold greater affinity to a defined G4 DNA sequence. The preference for G4 DNA is retained by the Timeless-Tipin complex.

\section{The Timeless C-terminus is crucial for processive $G 4$ replication in vivo}

To further explore the in vivo contribution of Timeless C-terminus to G4 replication, we generated a DT40 cell line expressing a version of Timeless truncating the gene before the DBD, using CRISPR-Cas9 gene targeting to exon 16. This truncation also removes a domain previously reported to bind PARP1, the PARP1-binding domain (PBD) ${ }^{49}$. This cell line 
exhibits instability of $B U-1$ expression comparable to the timeless mutant (Fig. 4) suggesting a role for the $\mathrm{C}$ terminus of the protein in $\mathrm{G} 4$ replication. To further dissect this observation, we complemented timeless cells with truncated versions of human Timeless, lacking only the DBD $(\triangle \mathrm{DBD})$ or the PBD (PARP*). Timeless lacking each of these domains individually largely, but not completely, restores the $B U-1$ expression instability of the timeless mutant suggesting that they act redundantly. Additionally, co-immunoprecipitation experiments show that neither region is required for binding the DDX11 helicase (Supplementary Fig. 5), a known binding partner of Timeless and whose ability to unwind G4s is stimulated by Timeless ${ }^{36}$. These results indicate that the $\mathrm{C}$ terminus of the Timeless protein has an important role in G4 replication with the DBD and the PDB both contributing to that function independently of DDX11 recruitment.

\section{$D D X 11$ ensures processive $G 4$ replication in vivo}

Since Timeless itself lacks any catalytic activity, we next explored the extent to which the genetic interaction between Timeless and the DDX11 helicase accounted for G4 processing in this system. As noted above, Timeless interacts with DDX11 29,36,50, and this interaction has been shown to be important for sister chromatid cohesion ${ }^{50}$ and preservation of fork progression in perturbed conditions ${ }^{36}$. Further, in vitro, DDX11 can unwind several DNA structures including G4s ${ }^{38-40}$ and the activity of DDX11 is stimulated by Timeless ${ }^{36}$. Recent work has shown that DDX11 interacts with Timeless through a domain in exon $4{ }^{50}$. We therefore examined $B U-1$ stability both in a $d d x 11$ mutant generated by conventional gene targeting, which disrupts exons $7-12$ downstream of the Timeless interaction domain ${ }^{45}$ and in CRISPR/Cas9-generated deletion mutants that targets exon 4 and introduces downstream frameshifts disrupting expression of the Timeless interaction domain (Supplementary Fig. 1). The newly generated CRISPR/Cas9-generated $d d x 11$ mutants are sensitive to cisplatin (Supplementary Fig. 2), similar to the previously reported mutant generated by gene targeting 45 .

All $d d x 11$ mutants examined exhibited elevated rates of Bu-1 loss variant generation (Fig. 5a). This expression instability was supressed by complementation with full-length chicken DDX11, but not with the K87A helicase-dead form of DDX11 (the chicken equivalent of the human K50A mutation in the Walker A motif), demonstrating that the helicase activity of DDX11 is essential for G4 replication in vivo (Fig. 5b). Importantly, the $B U-1$ expression instability of $d d x 11$ cells is also dependent on the presence of the $+3.5 \mathrm{G} 4$ in $B U-1$ (Fig. 5b). 
DDX11 works with Timeless in preventing G4-dependent instability of BU-1 expression

We next asked whether DDX11 and Timeless participate in the same pathway for G4 resolution at the replication fork. We generated $d d x 11 /$ timeless double mutants by targeting Timeless in the CRISPR/Cas9-generated $d d x 11$ clone 1 cells. Fluctuation analysis showed that the doublemutant $d d x 1$ 1/timeless does not exhibit higher rates of $\mathrm{Bu}-1$ loss-variant formation, compared to the single Timeless or $d d x 11$ mutants (Fig. 5c). This suggests that these proteins act in the same pathway for G4 replication. This finding is in contrast to the genetic interaction between DDX11 and the FANCJ helicase, which also plays a prominent role in replication of G4s ${ }^{9-12}$. fancj DT40 exhibit instability of $B U-1$ expression ${ }^{44}$ that is dependent on the helicase activity of FANCJ (Supplementary Fig. 6). A double fancj/ddx 11 mutant ${ }^{51}$ exhibits significantly more $B U-1$ expression instability than either single mutant (Fig. 5d), suggesting that these helicases operate on the $B U-1$ G4 motif independently of each other.

Timeless and DDX11 deficiency leads to decreased proliferation and increased activation of DDR in presence of pyridostatin (PDS)

We next asked whether deficiency in Timeless and DDX11 exacerbates the globally detrimental cellular consequences of G4-binding ligands. We treated timeless, $d d x 11$, and $d d x 11 /$ timeless cells with the G4 ligand pyridostatin (PDS) ${ }^{52}$. All mutant cell lines, but not the wild type, exhibited an intrinsic reduction in doubling time with cellular proliferation further decreased in the presence the G4 ligand (Fig. 6a). We next looked at the induction of histone $\mathrm{H} 2 \mathrm{AX}$ phosphorylation $(\gamma-\mathrm{H} 2 \mathrm{AX})$ using permeabilised cell flow cytometry. We have previously observed that PDS induces little or no $\gamma$-H2AX in wild type DT40 cells ${ }^{43}$ and this was also true in our cytometric assay. However, timeless, and $d d x 11$ mutants both exhibit increased levels of $\gamma$-H2AX (detected by flow cytometry) following treatment with $4 \mu \mathrm{M}$ PDS for 3 days compared with wild type cells (Fig. $6 \mathrm{~b} \& \mathrm{c}$ ). $\gamma$-H2AX levels in the double ddx11/timeless mutant after PDS treatment were not significantly higher than the timeless single mutant, again supporting the observation that these the two proteins operate in the same pathway for avoiding G4 ligand-induced DNA damage signalling.

Deficiency of DDX11 and Timeless leads to dysregulation of a common set of genes harbouring G4s in close proximity to their TSS

We have previously reported that the instability of expression of the $B U-1$ locus in mutants defective in G4 replication is observed in other loci genes across the genome ${ }^{44,53}$. We have 
shown that correlations between the identity of the genes dysregulated in different mutants, along with the direction and magnitude of those changes, can be used to infer genetic relationships between G4 processing enzymes ${ }^{44,53}$. We applied this approach to the relationship between Timeless and DDX11, assessing gene expression changes with RNA-seq. Loss of DDX11 or Timeless induced marked changes in gene expression (timeless 1752; $d d x 11$ 821 genes with altered expression at $\mathrm{p}>0.95$ ), with an approximately equal number of genes being up- or down-regulated (Supplementary Fig. 7a) in both cases. Moreover, there was a significant $\left(\mathrm{p}<2.2 \times 10^{-16}\right)$ overlap in the identity of the deregulated genes in timeless and $d d x 11$ cells (Supplementary Fig. 7b) and a significant correlation (Spearman correlation 0.82, $p$ value $<10^{-16}$ ) both in the magnitude and direction of the change in expression at the level of individual genes (Fig. 7a). Consistent with our model ${ }^{42}$, genes dysregulated in timeless and $d d x 11$ mutants are more likely to harbour a G4 close to their TSS. Using a G4 regex of $\left(\mathrm{G}_{3} \mathrm{~N}_{12}\right)_{3} \mathrm{G}_{3}$, we found that the region $1.5 \mathrm{~kb}$ around the TSS in genes dysregulated in timeless and $d d x 11$ is enriched for G4 motifs relative to all genes (Fig. 7b), an observation that is not simply explained by a higher GC content (Fig. 7c). Further, the enrichment of G4s near the TSS was similar to that seen in cells lacking the FANCJ helicase (Fig. 7b \& 7d) and the changes in gene expression in timeless and $d d x 11$ also correlated strongly with those observed in fancj cells, which we have previously studied ${ }^{44,53}$ (Supplementary Fig. 7c, Spearman correlation 0.9 , $\mathrm{p}$ value $<10^{-16}$ ), providing further support for a common, G4-dependent mechanism for the gene dysregulation in these three mutants. Together, these results suggest that DDX11 and Timeless collaborate to ensure expression stability through replication of a subset of genes with G4s close to their transcription start site.

\section{Discussion}

Accumulating genetic evidence suggests that DNA secondary structure formation is a frequent challenge to vertebrate DNA replication ${ }^{3}$. Numerous factors collaborate to ensure that these structures do not result in persistent stalling of DNA synthesis or that the resulting tracts of single strand DNA formation are limited, for instance by efficient repriming ${ }^{4}$. By limiting uncoupling of DNA unwinding and DNA synthesis, these mechanisms prevent both genetic and epigenetic instability. 
A key to ensuring that polymerase pausing at secondary structures does not lead to extensive single stranded DNA formation should be efficient sensing of structure formation by the replisome coupled to the recruitment of factors that will remove the structure and, if needed, reprime DNA synthesis. However, it remains to be established how secondary structure formation on the DNA template is detected by the replisome.

Timeless, along with other components of the FPC, appears to be a constitutive component of the core replisome ${ }^{54}$. Although not essential for DNA replication, the FPC increases the speed and efficiency of fork progression and DNA synthesis ${ }^{22}$. The intimate association of the FPC with the replisome potentially puts it in an ideal place to coordinate the response of the replisome to secondary structure formation. Indeed, loss of components of the FPC leads to instability of structure-forming repeat sequences ${ }^{31,32,34,35,55}$.

Here we show that the C-terminus of Timeless contains a DNA binding domain (DBD) that is able to bind G4 DNA more avidly than unstructured single and double stranded DNA in vitro. Using a sensitive in vivo assay that monitors episodes of replication pausing at a defined secondary structure forming sequence, we show that Timeless is required to maintain processive replication of G4 DNA. This requires the C-terminus of the protein, which contains both the newly identified DBD and an adjacent domain previously shown to bind PARP1 49,56. Interestingly, cells expressing Timeless lacking either domain exhibit significant, although not complete, complementation suggesting that there is significant redundancy between these two domains. The precise role of PARP1 in G4 sensing during replication remains to be explored, but it is noteworthy that PARP1 has been previously reported to bind G4 DNA in vitro ${ }^{57}$ suggesting, potentially, that Timeless could recognise G4s both directly through its DNA binding domain and indirectly via recruitment of PARP1 to the G4.

Timeless has also been shown to interact with the G4 helicase DDX11 and this interaction stimulates the helicase activity of DDX1 ${ }^{36}$. We have shown here that loss of Timeless and DDX11 are epistatic for G4-induced $B U-1$ expression instability consistent with them operating as a unit. Interestingly, loss of both DDX11 and the related G4-unwinding Fe-S helicase, FANCJ, result in more rapid generation of Bu-1 loss variants than either single mutant suggesting that these two helicases independently contribute to replication of a the $+3.5 \mathrm{BU}-1$ G4. Our analysis of genome wide gene expression dysregulation suggests that this division of 
labour between DDX11/Timeless and FANCJ is likely to be extended to other G4s in the genome.

Much work remains to be done to dissect the interactions between protein factors that process G4s and other fork-stalling DNA structures, to ensure smooth progress of DNA synthesis. Mechanistically, advances in replisome structural biology should help inform where G4 sensing by Timeless takes place relative to the CMG helicase. It is reasonable to anticipate that it will detect G4s forming transiently in the negatively supercoiled DNA emerging from CMG (Fig. 7e). The large size and multi-domain structure of Timeless indicates that its DBD could also reach and interact with DNA structures within a wide radius around the fork. This could potentially include those structures present in the DNA before it reaches CMG (Fig. 7f). Such structures might then be 'traversed' by the helicase, analogous to its proposed behaviour at a DNA-protein crosslink \{Sparks et al., 2019, \#91435\}, before stalling the leading strand polymerase $\{$ discussed further in Lerner and Sale, 2019, \#92536\}. In either case, detection and resolution of the structure will ensure the smooth execution of DNA synthesis, avoiding the generation of potentially deleterious ssDNA.

\section{Methods}

\section{Molecular cloning}

Oligonucleotide sequences can be found in Supplementary Table 1. The Timeless DNA binding domain deletion ( $\triangle \mathrm{DBD}$ ) and PARP-binding domain truncation mutant plasmids were constructed by PCR. pcDNA4-Flag-hTimeless was linearized with PCR using outward primers flanking the DNA binding domain (fragment 816-965) or the PARP1-binding domain (V1000$\mathrm{XX}$ ). $10 \mathrm{fmol}$ mutant plasmids were recircularised (through the overlapping sequences) via Gibson assembly $\left(1 \mathrm{~h}, 50^{\circ} \mathrm{C}\right)$. Recombinant DNA was treated with $10 \mathrm{U}$ of $D p n \mathrm{I}$ to minimize carryover of the original plasmid, and transformed into DH5 $\alpha$ competent bacteria. Correct mutagenesis was confirmed by restriction digest and Sanger sequencing.

FANCJ point mutations were generated by site-directed mutagenesis using a Quick Change II XL Site-Directed Mutagenesis Kit (Agilent), according to the manufacturer's instructions, in the pEAK8-CFP-hFANCJ plasmid (generated in this study). This plasmid was generated by digesting a CFP-containing plasmid, a hWT FANCJ cDNA-plasmid and a pEAK8 backbone 
plasmid with HinDIII and SalI, SalI and NotI and HinDIII and NotI, respectively. All fragments were gel-purified with a QIAEX II Gel Extraction Kit (QIAGEN) and ligated in a three-way ligation reaction using a Rapid Ligation Kit (Merck) for 30 minutes at room temperature.

\section{Cell lines and transfections}

All DT40 cell lines were cultured at $37^{\circ} \mathrm{C}$ in a humidified $10 \% \mathrm{CO}_{2}$ atmosphere in RPMI 1640 with Glutamax (Thermo Fisher Scientific) supplemented with 7\% fetal bovine serum (Thermo Fisher Scientific), 3\% chicken serum (Sigma-Aldrich), $50 \mu \mathrm{M}$ 2-mercaptoethanol and 1\% penicillin/streptomycin, as previously described ${ }^{59}$. HEK293T cells were cultured at $37^{\circ} \mathrm{C}$ in a humidified 5\% $\mathrm{CO}_{2}$ atmosphere in DMEM (Thermo Fisher Scientific) supplemented with 10\% fetal bovine serum and penicillin/streptomycin.

DT40 $d d x 11$ (CRISPR), timeless and $d d x 11 /$ timeless mutants were generated in this study by CRISPR-Cas9-mediated gene disruption. DT40 WT $B U-1^{\Delta \mathrm{G} 4}$ cells were generated by deleting the $+3.5 \mathrm{G} 4$ motif from both alleles of the BU-1 locus ${ }^{42}$. Other mutant lines have also been described previously: fancj ${ }^{44}, d d x 11$, fancj/ddx 11 and tipin ${ }^{45,51}$.

Complemented $d d x 11$ cells were obtained by transfecting the KO cell lines with pEGFP-C1 (Clontech) harbouring chicken DDX11 cDNA or a helicase-dead variant (K87A) ${ }^{45}$ with selection of G418-resistant ( $2 \mathrm{mg} / \mathrm{ml}$ ) clones followed by screening for GFP expression by flow cytometry. Complemention of timeless was achieved by transfection of plasmids encoding the human Timeless WT cDNA (Addgene plasmid 22887), or truncated versions thereof, selected with zeocin $(1 \mathrm{mg} / \mathrm{ml})$ followed by screening for Flag-positive clones by western blot. Complemented fancj cells were obtained as follows. First, fancj+/- cells harbouring a tamoxifen-regulatable Cre recombinase, Mer-Cre-Mer ${ }^{60}$ were transfected with pXSPN ${ }^{61}$ with wild type human YFP-FANCJ flanked by loxP sites. The second allele of the FANCJ locus was then disrupted with a previously described targeting construct ${ }^{44}$. For testing the effect of FANCJ mutations, a second pXPSN plasmid was introduced harbouring CFP-FANCJ[mut] without loxP sites, where 'mut' is the desired mutation. Treatment with tamoxifen results in excision of the wild type FANCJ transgene leaving the cells either FANCJ-deficient or solely expressing FANCJ[mut].

Transfections for CRISPR-Cas9 targeting were performed using a Neon electroporator (Thermo Fisher Scientific), $20 \times 10^{6}$ cells and $20 \mu \mathrm{g}$ plasmid DNA and 3 pulses of $1400 \mathrm{~V}$ with 
intervals of $10 \mathrm{msec}$. For cDNA expression either the Neon, with the same conditions, or a BioRad electroporator with 1 pulse of $250 \mathrm{~V} 950 \mu \mathrm{F} 100 \Omega$ in $4 \mathrm{~mm}$ cuvettes, was used.

\section{Gene disruption using CRISPR-Cas9}

Guide RNA sequences used for disrupting DDX11 and TIMELESS in DT40 cells are listed in Supplementary Table 1. Guide RNAs were designed using the CRISPOR online tool of the Zhang lab (https://zlab.bio/guide-design-resources). Each guide was cloned into the pSpCas9(BB)-2A-GFP (PX458) plasmid ${ }^{62}$ and transfected as described above. $24 \mathrm{~h}$ after transfection cells were collected by centrifugation at $400 \mathrm{~g}$ for 5 minutes and sorted at single live (PI-), GFP-positive cell per well in 96-well plates using a MoFlo (Beckman Coulter) or a Synergy (Sony) cell sorter. Cells were grown for 2 weeks, clones were collected and genotyped by Sanger sequencing of the targeted region amplified by PCR, gel-purified with a QIAquick Gel Extraction Kit (QIAGEN) and blunt-cloned using Zero Blunt TOPO PCR Cloning Kit (Thermo Fisher Scientific). Sequences were aligned against the WT DT40 genome using MacVector software.

\section{Bu-1 staining and fluctuation analysis for generation of Bu-1 loss variants}

$\mathrm{Bu}-1$ staining and fluctuation analysis were performed as described previously ${ }^{42,43}$. Briefly, cells (confluency between $0.4-2 \times 10^{6}$ ) were directly stained with anti-Bu-1 conjugated with phycoerythrin (Santa Cruz 5K98-PE 70447 or Invitrogen 21-1A4-PE MA5-28754) at 1:100 dilution for 10 minutes at room temperature. Cells were analysed by flow cytometry using an LSRII flow cytometer (Beckman Coulter) and the FloJo software. Bu-1 expression in single live cells was gated using side scatter (SSC) in the y-axis and PE fluorescence in the x-axis. To perform fluctuation analysis, $\mathrm{Bu}-1$-positive single cells were sorted and grown for $\sim 20$ generations before staining and flow cytometry analysis as described above.

\section{G-quadruplex ligand}

The small molecule pyridostatin (PDS) ${ }^{52}$ was purchased from Sigma-Aldrich.

\section{Cell proliferation and viability assays}

$5 \times 10^{5}$ cells were seeded in $10 \mathrm{~cm}$ dishes containing $10 \mathrm{ml}$ of media with G4 ligand/DMSO. Living cells were counted at 24, 48, 72 and $96 \mathrm{~h}$ on a Vi-Cell cell counter (Beckman Coulter). Doubling time was calculated during the exponential growth phase using the formula Doubling Time $=$ duration $* \log (2) / \log ($ Final Concentration $)-\log ($ Initial Concentration $)$. 
Cell viability was determined $72 \mathrm{~h}$ after PDS or cisplatin treatment using a CellTiter 96 AQueous One Solution Cell Proliferation Assay (Promega), according to the manufacturer's instructions. $1 \times 10^{5}$ cells/well were seeded in 96-well plates in $200 \mu 1$ media containing PDS or cisplatin. $72 \mathrm{~h}$ later, $20 \mu \mathrm{l}$ of MTS reagent was added to $100 \mu \mathrm{l}$ cells and incubated for 2-4 h at $37^{\circ} \mathrm{C}$. Absorbance was measured at $492 \mathrm{~nm}$ (formazan salt) in a PHERAstar plate reader (BMG Labtech). The percentage of cell viability was calculated as follows: Cell viability (\%) $=($ Test absorbance/Control absorbance $) * 100$.

\section{Flow cytometry to monitor $\gamma-H 2 A X$}

Cells were collected, fixed with 1\% paraformaldehyde for 15 minutes in ice, washed with PBS and fixed with $70 \%$ ethanol for at least $24 \mathrm{~h}$ at $-20^{\circ} \mathrm{C}$. Cells were blocked and permeabilized in BD wash/permeabilization Buffer (BD Biosciences) and then incubated with anti- $\gamma-\mathrm{H} 2 \mathrm{AX}$ antibody (05-636, Merck, diluted at 1:500 in BD Buffer) for $2 \mathrm{~h}$ at room temperature. Samples were washed twice with BD Buffer, incubated with anti-mouse AF594 antibody (A11062, Thermo Fisher Scientific, diluted at 1:200 in BD Buffer) for $1 \mathrm{~h}$ at room temperature in the dark, and then washed twice with BD Buffer. Cells were resuspended in PBS containing 0.5\% BSA and $1 \mu \mathrm{g} / \mathrm{ml}$ DAPI. Cells were analysed by flow cytometry using an LSRII flow cytometer (Beckman Coulter) and the FloJo software. A gate for $\gamma$-H2AX-positive cells was defined based on untreated cells that were considered negative for $\gamma-\mathrm{H} 2 \mathrm{AX}$ staining (see Fig. 6b).

\section{Protein expression and purification}

Full-length human Timeless (1-1208) was amplified from I.M.A.G.E cDNA clone IRATp970C0576D (Source Bioscience) and cloned into pRSF-Duet1 (Novagen) with an Nterminal His $14-S U M O$ tag. Our previous structural analysis had demonstrated that residues 239330 comprise a large disordered loop within the folded N-terminal region of Timeless ${ }^{63}$ and their removal improved dramatically the biochemical behaviour of the protein; they were therefore replaced by a short linker consisting of residues (Gly-Ser-Thr)2. All experiments reported here were performed with this optimised Timeless construct. The full-length human Tipin gene (1-301) was codon-optimised for E. coli expression (Life Technologies), and cloned into the pGAT3 vector for expression fused to an N-terminal His 6 -GST tag ${ }^{64}$. Timeless and Tipin were co-expressed in E. coli Rosetta2 (DE3). The complex was purified using Ni-NTA agarose (Qiagen) followed by cleavage of the tags with TEV and SUMO proteases, ion exchange chromatography (HiTrap Q HP, GE Healthcare) and size-exclusion chromatography 
(Superdex 200 16/60, GE Healthcare). The DNA-binding domain of human Timeless (DBD; residues 816-954) was cloned into pRSF-Duet1 (Novagen) with an N-terminal His ${ }_{14}$-SUMO tag and expressed in E. coli Rosetta2 (DE3). Purification entailed Ni-NTA agarose (Qiagen), His $_{14}$-SUMO tag cleavage with SUMO protease, Ni-NTA re-capture of the cleaved tag and size-exclusion chromatography (Superdex 75 16/60, GE Healthcare). Timeless 883-947 (DBD C-term) was expressed and purified in the same way as DBD.

\section{$X$-ray crystal structure determination}

The DBD C-term was crystallised by vapour diffusion, mixing equal volumes of protein at 800 $\mu \mathrm{M}$ and a solution of $200 \mathrm{mM}$ sodium formate and $18 \%$ PEG 3350 at $19^{\circ} \mathrm{C}$. For cryoprotection of the crystals the mother liquor was replaced with a 2:2:1 (volume ratio) mixture of reservoir solution, protein buffer and $100 \%$ glycerol. X-ray diffraction data for a native crystal was collected at the I24 beam line at Diamond Light Source, Oxford, UK. The dataset was processed with XDS ${ }^{65}$ in space group P65 to a resolution of $1.15 \AA$.

For structure determination by anomalous scattering, crystals were grown of Se-Met labelled DBD. Selenomethionine was incorporated in the DBD using metabolic inhibition in the presence of Se-Met during bacterial expression in minimal media. Diffraction data at the peak wavelength of $0.9793 \AA$ was collected at the Proxima2A beam line of the Soleil Synchrotron, Gif-sur-Yvette, France. The data was processed to $2.4 \AA$ with XDS ${ }^{65}$ in the same space group and cell dimensions as for the native crystal. The structure was solved exploiting the anomalous signal of the peak dataset using Autosol (Phenix) ${ }^{66}$. A largely complete Se-Met model was used to solve the native dataset by molecular replacement using PHASER ${ }^{67}$. The model of the resulting solution was subsequently extended by Autobuild (Phenix) ${ }^{66}$ and completed by iterative cycles of manual building and model refinement in Coot ${ }^{68}$ and Phenix ${ }^{66}$. The structural figures were generated with Chimera ${ }^{69}$.

\section{NMR spectroscopy}

For expression of ${ }^{15} \mathrm{~N}$ - or ${ }^{13} \mathrm{C},{ }^{15} \mathrm{~N}$-labeled Timeless $816-954,{ }^{13} \mathrm{C}_{6}$-glucose and/or ${ }^{15} \mathrm{NH}_{4} \mathrm{Cl}$ was used as the sole carbon/nitrogen source in M9 minimal medium. NMR measurements were made on $\sim 0.5 \mathrm{mM}$ solutions in $10 \%{ }^{2} \mathrm{H}_{2} \mathrm{O}, 10 \mathrm{mM}$ phosphate (pH 6.4), $40 \mathrm{mM} \mathrm{KCl}, 0.5 \mathrm{mM}$ EDTA. Experiments were recorded at $25{ }^{\circ} \mathrm{C}$ on Bruker AVANCE III 600 or $800 \mathrm{MHz}$ spectrometers equipped with QCI or TXI cryoprobes. Data were processed using the AZARA 
suite of programs (v. 2.8, (C) 1993-2019; Wayne Boucher and Department of Biochemistry, University of Cambridge, unpublished). Backbone assignments were derived from established versions ${ }^{70}$ of $\mathrm{HNCA}, \mathrm{HN}(\mathrm{CO}) \mathrm{CA}, \mathrm{HN}(\mathrm{CO}) \mathrm{CACB}, \mathrm{HNCACB}$ and $\mathrm{HNCO}$ experiments acquired with non-uniform sampling, and side chains using 3D (H)CC(CO)NH-TOCSY, TOCSY- ${ }^{15} \mathrm{~N}-\mathrm{HSQC}, \quad$ NOESY- ${ }^{15} \mathrm{~N}-\mathrm{HSQC}, \quad \mathrm{HC}(\mathrm{C}) \mathrm{H}-\mathrm{TOCSY}$ and NOESY- ${ }^{13} \mathrm{C}-\mathrm{HSQC}$. Assignment was carried out using CcpNmr Analysis v. $2.4^{71}$. For the heteronuclear NOE experiments, either $4 \mathrm{~s}$ of ${ }^{1} \mathrm{H}$ saturation using a $120^{\circ}$ pulse train or a 4-s delay was employed prior to the first ${ }^{15} \mathrm{~N}$ pulse. Inter-proton distance restraints were derived from NOE peak heights in the 3D NOESY spectra using the relaxation matrix method (which accounts for spin diffusion) and $\mathrm{r}^{-6}$ summation for ambiguous NOEs. Backbone $\phi$ and $\psi$ torsion-angle restraints were obtained using TALOS $+{ }^{72}$. The restraints provided the input for the iterative assignment protocol ARIA v.1.2 $2^{73}$. For the final iteration, 100 structures were calculated with the violation tolerance set to $0.1 \AA$. After the last iteration, the 20 lowest-energy structures were subjected to a final water refinement to give an ensemble of 20 structures. Torsion-angle molecular dynamics simulations were performed using CNS ${ }^{74}$. The simulated annealing protocol used to calculate each structure included 60,000 molecular dynamics steps, including those for refinement, and two cooling stages (to $1000 \mathrm{~K}$ and $50 \mathrm{~K}$ ).

\section{EMSA-based DNA binding experiments}

G-quadruplex sequences (Supplementary Table 2) were folded by heating the DNA to $95^{\circ} \mathrm{C}$ followed by gradual cooling to $10^{\circ} \mathrm{C}$, in TE buffer supplemented with $150 \mathrm{mM} \mathrm{KCl}$. Reactions contained $5 \mu \mathrm{M}$ Timeless-Tipin and $5 \mu \mathrm{M}$ 6FAM-labelled DNA in $25 \mathrm{mM}$ HEPES pH 7.1, 150 $\mathrm{mM} \mathrm{KCl}, 5 \mathrm{mM} \mathrm{MgCl} 2$ and $1 \mathrm{mM}$ DTT. Reactions were incubated on ice for 30 minutes, after which native loading dye was added and the samples analysed on a $1 \%$ agarose gel in EMSA buffer $(0.5 \mathrm{x}$ TBE, $10 \mathrm{mM} \mathrm{KCl})$. Gels were run for 1 hour at $50 \mathrm{~V}$ and $4{ }^{\circ} \mathrm{C}$, and bands were visualized under UV light.

Fluorescence anisotropy analysis of DBD domain and Timeless-Tipin complex binding to $D N A$.

DNA sequences were annealed by heating to $95^{\circ} \mathrm{C}$ followed by gradual cooling to $10^{\circ} \mathrm{C}$, using a thermocycler, in TE buffer supplemented with $150 \mathrm{mM} \mathrm{KCl}$. Fluorescence anisotropy measurements were recorded at $25^{\circ} \mathrm{C}$ in a plate reader (PHERAstar FS; BMG Labtech). Excitation for Cy3-3'labeled DNA was at $540 \mathrm{~nm}$ and emission at $590 \mathrm{~nm}$ (20 nm bandwidth 
for both). Excitation for FAM6-5' labeled DNA was at $485 \mathrm{~nm}$ and emission at $520 \mathrm{~nm}(10 \mathrm{~nm}$ bandwidth for both). For DBD titrations, each well contained $10 \mathrm{nM}$ 3'Cy3-labelled DNA and increasing concentrations of DBD protein in assay buffer ( $25 \mathrm{mM}$ HEPES-NaOH pH 7.2, 150 $\mathrm{mM} \mathrm{KCl}, 0.5 \mathrm{mM}$ EDTA, 0.005\% Tween-20). For Timeless-Tipin complex titrations, each well contained $10 \mathrm{nM} 6 \mathrm{FAM}$-labelled DNA, and increasing concentrations of the complex in assay buffer (25 mM HEPES pH 7.1, $150 \mathrm{mM} \mathrm{KCl,} 1 \mathrm{mM}$ DTT, $5 \mathrm{mM} \mathrm{MgCl}$ ). The voltage gains and focal heights were adjusted using the instrument software using free fluorescein as reference $(35 \mathrm{mP})$ and data collection was set to 200 flashes. Each data point is the mean of at least 3 independent measurements. The averaged data was analysed using nonlinear fits of ligand-depletion binding isotherms adapted for fluorescence-anisotropy measurements, assuming one to one binding model and using the ProFit software package (Quantum Soft). No corrections were necessary for changes in the quantum yield as a function of protein concentration.

\section{Co-immunoprecipitation (Co-IP) and Western Blot (WB)}

For whole-cell extracts, the protein samples were lysed in Lysis Buffer (50 mM Tris-HCl pH 7.5, $20 \mathrm{mM} \mathrm{NaCl}, 1 \mathrm{mM} \mathrm{MgCl}$, $0.1 \%$ SDS, protease inhibitors (Complete Protease Inhibitor Cocktail Tablets, Merck), phosphatase inhibitors (Halt Phosphatase Inhibitor Cocktail (Thermo Fisher Scientific) and $1 \mu \mathrm{l} / \mathrm{ml}$ benzonase (Merck)) for $15 \mathrm{~min}$ at room temperature under agitation, and cleared by centrifugation at $16000 \mathrm{~g}$ for $20 \mathrm{~min}$ at $4^{\circ} \mathrm{C}$. Samples were quantified using the Bradford method and approximately $30 \mu \mathrm{g}$ were mixed with 5X SDS Page Sample Buffer (Jena Bioscience), boiled for $3 \mathrm{~min}$, fractionated in 4-12\% or 10\% Nu-PAGE Bis-Tris gels (Thermo Fisher Scientific) in MOPS (200 mM MOP, $50 \mathrm{mM}$ Sodium Acetate, $10 \mathrm{mM}$ $\mathrm{Na}_{2}$ EDTA), and transferred to nitrocellulose membranes using an iBlot2 apparatus (Thermo Fisher Scientific) at $25 \mathrm{~V}$ for $7 \mathrm{~min}$. Membranes were blocked for $1 \mathrm{~h}$ at room temperature with TBS 0.1\% Tween-20 5\% skimmed milk. Membranes were incubated with primary antibodies diluted in TBS-T 5\% milk overnight at $4{ }^{\circ} \mathrm{C}$ under agitation, washed with three washes of 10 min each with TBS-T, and incubated with HRP-conjugated secondary antibodies at room temperature for $1 \mathrm{~h}$, followed by three washes with TBS-T. Membranes were developed with Immobilon Crescendo Western HRP substrate (Merck) for 1 min and exposed to X-ray films.

For Co-IP experiments, pcDNA4-Flag-Timeless plasmids (WT and truncated versions) were co-transfected into $2 \times 10^{6}$ HEK293T cells using Lipofectamine 2000 (Thermo Fisher 
Scientific) seeded in $10 \mathrm{~cm}$ dishes $16 \mathrm{~h}$ prior to transfection ( $80 \%$ confluency at transfection) with pcDNA3-hDDX11 ${ }^{45}$ (30 $\mu \mathrm{g}$ total DNA). $24 \mathrm{~h}$ after transfection, cells were detached with trypsin and washed in cold PBS. Pellets were lysed in NETN-M buffer with glycerol $(150 \mathrm{mM}$ $\mathrm{NaCl}, 50 \mathrm{mM}$ Tris- $\mathrm{HCl} \mathrm{pH} 8,0.5 \%$ Igepal, $1 \mathrm{mM}$ EDTA, $5 \mathrm{mM} \mathrm{MgCl}_{2}$ and $10 \%$ glycerol, supplemented with protease and phosphatase inhibitors) and benzonase for $15 \mathrm{~min}$ at room temperature under agitation. Samples were sonicated with 8 cycles of 30 s with 30 s intervals at the low setting in a Bioruptor Plus water bath sonicator (Diagenode) and centrifuged for 15 min at $16000 \mathrm{~g}$ at $4^{\circ} \mathrm{C}$. Supernatant was collected, quantified and $2 \mathrm{mg}$ of total cell extract were mixed with $30 \mu$ Flag-M2 magnetic beads (M8823, Sigma-Aldrich). Samples were incubated at $4^{\circ} \mathrm{C}$ for $2 \mathrm{~h}$ under agitation. Beads were then washed 5 times for $5 \mathrm{~min}$ each with lysis buffer, and proteins were eluted by boiling with Sample Buffer Laemli 2X (Sigma-Aldrich) for 5 min at $95^{\circ} \mathrm{C}$. Samples were subjected to analysis by WB as described above, using the indicated antibodies.

Primary antibodies used: mouse anti-Flag (M2 F3165, Merck), mouse anti-DDX11 (D-2 271711, Santa Cruz) and mouse anti- $\alpha$-tubulin (T6074, Sigma). Secondary antibody: goat antimouse HRP (P0447 Dako).

\section{$R N A$ extraction and $R N A$-seq library preparation}

RNA was extracted from three independent cell populations using the RNeasy Mini Kit (QIAGEN), according to the manufacturer's instructions. RNA sample quality was checked in BioAnalyzer RNA Pico chips (Agilent) and only high quality samples (RIN > 7) were used to build the libraries. $750 \mathrm{ng}$ RNA were used to build the next generation sequencing libraries with the NEBNext Ultra II RNA Library Prep Kit for Illumina (New England BioLabs), NEBNext Poly(A) mRNA Magnetic Isolation Module and NEBNext Multiplex Oligos for Illumina (Index Primers Set 1 and 2), according to the manufacturer's intructions. Library quality was checked in BioAnalyzer DNA High Sensitivity chips (Agilent), and quantified using the KAPA Library Quanti Kit (Illumina) Universal qPCR Mix (KAPA Biosystems) on an ABI Prism ViiA 7 Real-Time PCR System (Thermo Fisher Scientific). Libraries were sequenced on a HiSeq4000 (Illumina).

\section{$R N A$-seq library alignment}

RNA sequencing reads were aligned to the GRCg6a chicken genome using Bowtie $2{ }^{75}$. Expression estimates (transcripts per million; TPM) were calculated using the rsem-calculate- 
expression command of RSEM ${ }^{76}$ and the version 96 of the chicken genome gene annotation from Ensembl. Only transcripts with an expression above or equal at 1 TPM were considered for further analysis. Gene expression matrixes were built using rsem-generate-data-matrix and three independent biological replicates. Differentially expressed genes were called using EBseq ${ }^{77}$. Change in gene expression was estimated using the EBseq posterior Fold Change (PostFC) value and genes were considered differently expressed when the EBseq posterior probability of being differentially expressed (PPDE) was above or equal at 0.95 .

\section{Promoter sequence analysis}

Gene promoter sequences were recovered from the GRCg6a chicken genome assembly using the getfasta command of BEDTools ${ }^{78}$. Sequence analyses were performed using custom scripts in the R environment (http://www.R-project.org/). Assessment of the enrichment of Gquadruplexes within the promoter of DDX11- and TIMELESS-dependent genes was based on regular expression matching algorithms to monitor the cumulative count of the G3N12 motif within promoters. This was computed by identifying the number of sequences of the form $\mathrm{d}\left(\mathrm{G}_{3}+\mathrm{N}_{1-12} \mathrm{G}_{3}+\mathrm{N}_{1-12} \mathrm{G}_{3}+\mathrm{N}_{1-12} \mathrm{G}_{3}\right)$, where $\mathrm{N}$ is any base, which represents the loose definition of G4 forming sequences ${ }^{79}$. Densities of G-quadruplex forming sequences around promoters were computed by assessing the number of promoter sequences containing sequences of the form $\mathrm{d}\left(\mathrm{G}_{3}+\mathrm{N}_{1}+\mathrm{G}_{3}+\mathrm{N}_{1+} \mathrm{G}_{3}+\mathrm{N}_{1}+\mathrm{G}_{3}\right)$ in windows of 50 nucleotides sliding by 10 nucleotides normalised to the total number of promoter sequences analysed.

\section{Statistical analysis of RNA-seq data}

Data were analysed and statistics performed in the R environment. Overlaps between gene lists were tested using Fisher's exact tests. Differences between distributions were tested using Kolmogorov-Smirnov tests. 


\section{Figure Legends}

Figure 1. Timeless and Tipin are required to maintain processive replication past G4 structures in vivo.

a. The $B U-1$ locus as a model system to record G4-dependent replication stalling . The leading strand of a replication fork entering the locus from 3' end stochastically stalls at the $+3.5 \mathrm{G} 4$, leading to the formation of a region of ssDNA, with interruption of parental histone recycling and of histone modifications necessary to maintain normal expression of the locus ${ }^{42}$. $\mathbf{b}$. Instability of $B U-1$ expression in timeless cells. FACS plots of wild type and timeless (clone 1) DT40 cells stained with anti-Bu-1 conjugated with phycoerythrin. Each line represents the Bu1 expression profile of an individual clonal population. Unstained controls are shown in blue. c. Fluctuation analysis for Bu-1 loss in wild-type DT40 cells and two independent timeless clones generated by CRISPR-Cas9 targeting (clones 1 and 2; Supplementary Fig. 1), timeless (clone 1) complemented by expression of human Timeless cDNA and a timeless mutant on a background in which the endogenous $+3.5 \mathrm{G} 4$ has been deleted $(\Delta \mathrm{G} 4)^{42}$. d. Fluctuation analysis for Bu-1 loss in DT40 wild-type and tipin cells. In c. and d., each symbol represents the percentage of cells in an individual clone expanded for 2-3 weeks that have lost $\mathrm{Bu}-1^{\text {high }}$ expression. At least two independent fluctuation analyses were performed, with 24-36 individual clones each cell line per repeat. Bars and whiskers represent median and interquartile range, respectively. $* * * * \mathrm{p}<0.0001$; one-way ANOVA.

\section{Figure 2. Identification and characterisation of a DNA-binding activity in Timeless}

a. Schematic drawing of human Timeless, showing its domain structure, interacting proteins Tipin and Parp1, and its DNA-binding domain (DBD). A multiple sequence alignment of vertebrate Timeless sequences is shown underneath, with amino acid conservation coloured according to the Clustal colour scheme. The alignment is annotated with the extent and secondary structure elements of the two helical domains (N-term and C-term) composing the DBD. b. Ribbon drawing of the $1.15 \AA$ crystal structure at of the DBD C-term. Helices are in red and labelled $\mathrm{H} 1$ to H4. c. Ribbon drawings of the N-term and C-term domains of the DBD determined by NMR. The two domains are shown in the same orientation to highlight their high degree of three-dimensional similarity. The superposition of the 20 lowest energy structures is shown for each domain. d. The DNA-binding affinity of DBD was measured by fluorescence anisotropy, titrating DBD protein against Cy3 3'-labelled ssDNA, dsDNA and Gquadruplex (G4) DNA. Top panel shows binding curves for ss- and dsDNA, the bottom panel 
shows the binding curve for the G4 DNA substrate. The data points represent the mean of at least 3 independent experiments and the error bars indicate one standard deviation (SD). e. Ribbon diagram of the superposition of DBD C-term with the highly similar DNA-binding domains of telomeric protein TRF1 (PDB ID 1W0T) ${ }^{46}$ and the bacterial cell-cycle regulator GcrA (PDB ID 5Z7I) ${ }^{47}$ in complex with their DNA substrates. A similar DNA-binding mode by DBD would cause a steric overlap of helix H4 with the phosphate backbone of dsDNA. DBD C-term is in light blue, TRF1 and GcrA proteins in brown and their DNA substrates in khaki.

Figure 3. The Timeless-Tipin complex shows a preference for binding G-quadruplex DNA.

Fluorescence anisotropy was used to measure the binding affinity of Timeless-Tipin for the indicated DNA sequences. a. ssG4: G4 flanked by single-stranded DNA; ssHP: hairpin flanked by single-stranded DNA; ss: single-stranded DNA; ds: double-stranded DNA (see Supplementary Table 2 for sequence details). b. Binding affinity of Timeless-Tipin for a range of G-quadruplex DNA sequences (see Supplementary Table 2 for sequence details and references). Single-stranded (ss20: 5'-6FAM-ATAAGAGTGGTTAGAGTGTA) and doublestranded (ds20: ss20 annealed to complementary sequence) DNA were also tested as controls. Each data point is the mean of at least 3 independent experiments and the error bars indicate one SD.

Figure 4. The C-terminus of Timeless is required for processive G4 replication. Fluctuation analysis for the generation of Bu-1 loss variants in wild-type cells, timeless (clone 1) cells, timeless (clone 1) complemented with human Timeless $\triangle \mathrm{DBD}$ cDNA (hTim $\triangle 81-965)$ and timeless (clone 1) complemented with human Timeless truncated at the PARP binding domain (hTim[1:1000]) cDNA and timeless cells generated by CRISPR-Cas9 targeting exon 16 which truncates the protein removing the CTD containing both the DBD and the PARP binding domains. At least two independent fluctuation analyses were performed with 24-36 individual clones each cell line per repeat. Bars and whiskers represent median and interquartile range, respectively. ${ }^{*} \mathrm{p}<0.05$ and $* * * * \mathrm{p}<0.0001$; one-way ANOVA for comparison with the wild-type cells. 


\section{Figure 5. DDX11 is required for processive replication in collaboration with Timeless.}

a. Fluctuation analysis for Bu-1a loss in wild-type DT40 cells, two independent $d d x 11$ clones generated by CRISPR-Cas9 targeting (clones 1 and 2) and one $d d x 11$ clone generated by conventional homologous recombination gene targeting (clone 3). Each symbol represents the percentage of cells in an individual clone expanded for 2-3 weeks that have lost $\mathrm{Bu}-1 \mathrm{a}^{\text {high }}$ expression. b. Fluctuation analysis for Bu-1a loss variant generation in wild-type cells, $d d x 11$ (clone 1) cells, $d d x 11$ (clone 1) complemented by expression of chicken DDX11 WT cDNA, ddx11 (clone 1) complemented by expression of helicase-dead form of chicken DDX11 (K87A) cDNA, and a $d d x 11$ clone generated in cells in which the endogenous $+3.5 \mathrm{G} 4$ has been deleted $(\Delta \mathrm{G} 4)$. c. Fluctuation analysis for Bu-1 loss in two independent $d d x 11 /$ timeless double-mutant clones. Fluctuation analyses for wild type, timeless (clone 1) and $d d x 11$ (clone 1) are shown for comparison, as are fluctuation analyses $f a n c j$ and $f a n c j / d d x 11$ double-mutants. In all cases, at least two independent fluctuation analyses were performed, with 24-36 individual clones each cell line per repeat. Bars and whiskers represent median and interquartile range, respectively. ${ }^{* *} \mathrm{p}<0.01$ and $* * * * \mathrm{p}<0.0001$; one-way ANOVA for comparison with wild-type cells.

Figure 6. Timeless and DDX11-deficient cells have impaired growth and increased $\mathrm{H} 2 \mathrm{AX}$ phosphorylation in the presence of a G4 ligand.

a. Growth curves for DT40 wild type, $d d x 11$, timeless and $d d x 11 /$ timeless cells, with and without $4 \mu \mathrm{M}$ pyridostatin (PDS). Cells were seeded at $5 \times 10^{4}$ cells $/ \mathrm{ml}$ on day 0 and the viable cells were counted each $24 \mathrm{~h}$ for 4 days. Bars represent SD of two independent experiments performed in duplicate. Doubling times (DMSO): WT 13 hours, timeless 18 hours, $d d x 1116$ hours, ddx11/timeless 24 hours. Doubling times (PDS): WT 13.6 hours, timeless 27 hours, $d d x 1125.7$ hours, $d d x 11 /$ timeless 47.5 hours. b. DDR signalling detected by phosphorylation of histone $\mathrm{H} 2 \mathrm{AX}(\gamma-\mathrm{H} 2 \mathrm{AX})$ by flow cytometry in untreated cells or cells exposed to $4 \mu \mathrm{M}$ PDS for 3 days. Pale histogram, untreated; dark histogram, treated; black dotted line, positive control cells treated with $0.1 \mu \mathrm{M}$ cisplatin, also for 3 days. c. Quantification of $\gamma-\mathrm{H} 2 \mathrm{AX}$ in DT40 wild type, $d d x 11$, timeless and $d d x 11 /$ timeless cells treated with $4 \mu \mathrm{M}$ PDS for 3 days. The whiskers represent the minimum to maximum variation of three independent experiments performed in duplicate. ${ }^{*} \mathrm{p}<0.05, * * \mathrm{p}<0.01,{ }^{* * *} \mathrm{p}<0.001$ unpaired, 2-tailed t-test for each pairwise comparison $+/$ - PDS. 
Figure 7. Loss of DDX11 and Timeless leads to genome wide expression dysregulation of genes with G4s around the transcription start site (TSS). a. Correlation of magnitude and direction of change of genes dysregulated (relative to wild type) in timeless vs. $d d x 11$ DT40 cells. $r_{s}$ (Spearman rho) is shown for each correlation. b. Cumulative distribution of genes containing n (x-axis) G4 motifs (see Methods) within 1.5kb of the TSS in genes deregulated in timeless (red) and $d d x 11$ (blue) compared with all genes (black). p values calculated with the Kolmogorov-Smirnov test. c. GC content around the TSS in in timeless (red) and $d d x 11$ (blue) compared with all genes (black). d. Metagene analysis showing G4 frequency (see Methods) separated for coding and template strands around the TSS of genes dysregulated in timeless (left panel), $d d x 11$ (centre panel) and fancj (right panel) mutants compared with all genes (black line). e \& f. Two models, which are not mutually exclusive, for how Timeless might detect G4s at the replication fork. e. Recognition of a G4 by the Timeless C-terminus formed in the negatively supercoiled ssDNA ejected behind the CMG helicase, possibly in conjunction with an interaction with PARP1 bound to the structure ${ }^{57}$ with recruitment of DDX11. Failure of this mechanism would lead to uncoupling of the replicative helicase and leading strand polymerase. For further discussion of this issue and how G4s might interact with the replisome, see Lerner \& Sale, $2019^{3}$. f. G4 detection and processing ahead of the CMG helicase. A leading strand G4 formed ahead of the replisome must be traversed by the CMG helicase, in an analogous manner to that proposed for traverse of an DNA interstrand crosslink ${ }^{58}$. This would lead the structure to stall the leading strand DNA polymerase and uncouple DNA unwinding and synthesis. Detection of the structure by the C-terminus of Timeless, Recruitment of DDX11 by Timeless would unwind the structure, obviating the need for further remodelling of the replicative helicase and preventing the structure meeting the leading strand polymerase.

\section{Competing interests}

The authors declare no competing interests.

\section{Data and Reagent Availability}

Coordinates and structure factors have been deposited in the Protein Data Bank (https://www.rcsb.org) under accession codes 6T9Q for the crystal structure of the C-terminal repeat of DNA-binding domain and 6TAZ (BMRB ID 34443) for the NMR structure of the DNA-binding domain. The RNA sequencing data has been deposited in GEO 
(https://www.ncbi.nlm.nih.gov/geo/) with accession number GSE139256. Requests for materials can be addressed to the corresponding authors.

\section{Author Contributions}

J.E.S., L.P., L.K.L. and S.H. conceived the overall project. L.K.L. generated the cell lines and performed the molecular biology experiments (flow cytometry, survival, IP, RNAseq). S.S. constructed the truncated versions of Timeless plasmids. D.S. generated the mer-cre-mer FANCJ cell line. P.M. performed the RNAseq data analysis. S.H. expressed and purified both DBD and DBD C-term, determined the x-ray crystal structure of the C-term, and performed the initial characterisation of the DNA-binding properties of the DBD. M.L.K., A.B. and J.D.M performed the DNA-binding experiments. K.S. and S.H. determined the NMR structure of the DBD. D.B. provided key KO cell lines. L.K.L., J.E.S. and L.P. wrote the initial manuscript with assistance and editing by all authors.

\section{Acknowledgements}

The authors thank M. Daly and F. Zhang in the LMB flow cytometry facility for cell sorting, Anno Koetje for help with the DNA-binding experiments, Joe Yeeles for discussions and members of both the Sale and Pellegrini groups for critical reading of the manuscript. Work in the Sale group is supported by a core grant to the LMB by the MRC (U105178808). L.K.L. received a 1-year Science Without Borders postdoctoral funding from the Coordenação de Aperfeiçoamento de Pessoal de Nível Superior (CAPES, Brasília, DF, Brazil). Work in the Pellegrini group is supported by a Wellcome Trust investigator award to L.P. (104641/Z/14/Z), a Boehringer-Ingelheim Fonds PhD fellowship and awards from the Janggen-Poehn-Stiftung and the Swiss National Science Foundation to S.H.

\section{References}

1. Mirkin, E. V. \& Mirkin, S. M. Replication fork stalling at natural impediments. Microbiol Mol Biol Rev 71, 13-35 (2007).

2. S Šviković, S. et al. R-loop formation during S phase is restricted by PrimPol-mediated repriming. EMBO J 38, (2019).

3. Lerner, L. K. \& Sale, J. E. Replication of G Quadruplex DNA. Genes (Basel) 10, 95 (2019).

4. Schiavone, D. et al. PrimPol Is Required for Replicative Tolerance of G Quadruplexes in Vertebrate Cells. Mol Cell 61, 161-169 (2016). 
5. Gellert, M., Lipsett, M. N. \& Davies, D. R. Helix formation by guanylic acid. Proc Natl Acad Sci U S A 48, 2013-2018 (1962).

6. Chambers, V. S. et al. High-throughput sequencing of DNA G-quadruplex structures in the human genome. Nat Biotechnol 33, 877-881 (2015).

7. Kaushal, S. \& Freudenreich, C. H. The role of fork stalling and DNA structures in causing chromosome fragility. Genes Chromosomes Cancer 58, 270-283 (2019).

8. Šviković, S. \& Sale, J. E. The Effects of Replication Stress on S Phase Histone Management and Epigenetic Memory. J Mol Biol 429, 2011-2029 (2017).

9. Wu, Y., Shin-ya, K. \& Brosh, R. M. FANCJ helicase defective in Fanconi anemia and breast cancer unwinds G-quadruplex DNA to defend genomic stability. Mol Cell Biol 28, 4116-4128 (2008).

10. London, T. B. et al. FANCJ is a structure-specific DNA helicase associated with the maintenance of genomic G/C tracts. J Biol Chem 283, 36132-36139 (2008).

11. Youds, J. L. et al. DOG-1 is the Caenorhabditis elegans BRIP1/FANCJ homologue and functions in interstrand cross-link repair. Mol Cell Biol 28, 1470-1479 (2008).

12. Kruisselbrink, E. et al. Mutagenic capacity of endogenous G4 DNA underlies genome instability in FANCJ-defective C. elegans. Curr Biol 18, 900-905 (2008).

13. Sarkies, P., Reams, C., Simpson, L. J. \& Sale, J. E. Epigenetic instability due to defective replication of structured DNA. Mol Cell 40, 703-713 (2010).

14. Dungrawala, H. et al. The Replication Checkpoint Prevents Two Types of Fork Collapse without Regulating Replisome Stability. Mol Cell 59, 998-1010 (2015).

15. Errico, A. \& Costanzo, V. Mechanisms of replication fork protection: a safeguard for genome stability. Crit Rev Biochem Mol Biol 47, 222-235 (2012).

16. Nedelcheva, M. N. et al. Uncoupling of unwinding from DNA synthesis implies regulation of MCM helicase by Tof1/Mrc1/Csm3 checkpoint complex. J Mol Biol 347, 509-521 (2005).

17. Numata, Y., Ishihara, S., Hasegawa, N., Nozaki, N. \& Ishimi, Y. Interaction of human MCM2-7 proteins with TIM, TIPIN and Rb. The Journal of Biochemistry 147, 917-927 (2010).

18. Cho, W. H. et al. Human Tim-Tipin complex affects the biochemical properties of the replicative DNA helicase and DNA polymerases. Proc Natl Acad Sci U S A 110, 25232527 (2013).

19. Bastia, D. et al. Phosphorylation of CMG helicase and Tof1 is required for programmed fork arrest. Proc Natl Acad Sci U S A 113, E3639-48 (2016).

20. Tanaka, T. et al. Fission yeast Swi1-Swi3 complex facilitates DNA binding of Mrc1. $J$ Biol Chem 285, 39609-39622 (2010).

21. Witosch, J., Wolf, E. \& Mizuno, N. Architecture and ssDNA interaction of the Timeless-Tipin-RPA complex. Nucleic Acids Res 42, 12912-12927 (2014).

22. Yeeles, J. T. P., Janska, A., Early, A. \& Diffley, J. F. X. How the Eukaryotic Replisome Achieves Rapid and Efficient DNA Replication. Mol Cell 65, 105-116 (2017).

23. Katou, Y. et al. S-phase checkpoint proteins Tof1 and Mrc1 form a stable replicationpausing complex. Nature 424, 1078-1083 (2003).

24. Lou, H. et al. Mrc1 and DNA polymerase epsilon function together in linking DNA replication and the S phase checkpoint. Mol Cell 32, 106-117 (2008).

25. Chou, D. M. \& Elledge, S. J. Tipin and Timeless form a mutually protective complex required for genotoxic stress resistance and checkpoint function. Proc Natl Acad Sci U $S$ A 103, 18143-18147 (2006).

26. Gotter, A. L., Suppa, C. \& Emanuel, B. S. Mammalian TIMELESS and Tipin are evolutionarily conserved replication fork-associated factors. J Mol Biol 366, 36-52 (2007). 
27. Unsal-Kaçmaz, K. et al. The human Tim/Tipin complex coordinates an Intra-S checkpoint response to UV that slows replication fork displacement. Mol Cell Biol 27, 3131-3142 (2007).

28. Yang, X., Wood, P. A. \& Hrushesky, W. J. Mammalian TIMELESS is required for ATM-dependent CHK2 activation and G2/M checkpoint control. J Biol Chem 285, 3030-3034 (2010).

29. Leman, A. R., Noguchi, C., Lee, C. Y. \& Noguchi, E. Human Timeless and Tipin stabilize replication forks and facilitate sister-chromatid cohesion. J Cell Sci 123, 660670 (2010).

30. Chan, R. C. et al. Chromosome cohesion is regulated by a clock gene paralogue TIM-1. Nature 423, 1002-1009 (2003).

31. Voineagu, I., Narayanan, V., Lobachev, K. S. \& Mirkin, S. M. Replication stalling at unstable inverted repeats: interplay between DNA hairpins and fork stabilizing proteins. Proc Natl Acad Sci U S A 105, 9936-9941 (2008).

32. Voineagu, I., Surka, C. F., Shishkin, A. A., Krasilnikova, M. M. \& Mirkin, S. M. Replisome stalling and stabilization at CGG repeats, which are responsible for chromosomal fragility. Nat Struct Mol Biol 16, 226-228 (2009).

33. Liu, G. et al. Replication fork stalling and checkpoint activation by a PKD1 locus mirror repeat polypurine-polypyrimidine (Pu-Py) tract. J Biol Chem 287, 33412-33423 (2012).

34. Leman, A. R. et al. Timeless preserves telomere length by promoting efficient DNA replication through human telomeres. Cell Cycle 11, 2337-2347 (2012).

35. Gellon, L. et al. Mrc1 and Tof1 prevent fragility and instability at long CAG repeats by their fork stabilizing function. Nucleic Acids Res 47, 794-805 (2019).

36. Calì, F., Bharti, S. K., Di Perna, R., Brosh, R. M. \& Pisani, F. M. Tim/Timeless, a member of the replication fork protection complex, operates with the Warsaw breakage syndrome DNA helicase DDX11 in the same fork recovery pathway. Nucleic Acids Res 44, 705-717 (2016).

37. Alkhunaizi, E. et al. Warsaw breakage syndrome: Further clinical and genetic delineation. Am J Med Genet A (2018).

38. Bharti, S. K. et al. Specialization among iron-sulfur cluster helicases to resolve Gquadruplex DNA structures that threaten genomic stability. J Biol Chem 288, 2821728229 (2013).

39. Wu, Y., Sommers, J. A., Khan, I., de Winter, J. P. \& Brosh, R. M. Biochemical characterization of Warsaw breakage syndrome helicase. J Biol Chem 287, 1007-1021 (2012).

40. Guo, M. et al. A distinct triplex DNA unwinding activity of ChlR1 helicase. $J$ Biol Chem 290, 5174-5189 (2015).

41. Liu, S. L. et al. TIMELESS confers cisplatin resistance in nasopharyngeal carcinoma by activating the $\mathrm{Wnt} / \beta$-catenin signaling pathway and promoting the epithelial mesenchymal transition. Cancer Lett 402, 117-130 (2017).

42. Schiavone, D. et al. Determinants of G quadruplex-induced epigenetic instability in REV1-deficient cells. The EMBO Journal 33, 2507-2520 (2014).

43. Guilbaud, G. et al. Local epigenetic reprogramming induced by G-quadruplex ligands. Nat Chem 9, 1110-1117 (2017).

44. Sarkies, P. et al. FANCJ coordinates two pathways that maintain epigenetic stability at G-quadruplex DNA. Nucleic Acids Res 40, 1485-1498 (2012).

45. Abe, T. et al. Chromatin determinants of the inner-centromere rely on replication factors with functions that impart cohesion. Oncotarget 7, 67934-67947 (2016). 
46. Court, R., Chapman, L., Fairall, L. \& Rhodes, D. How the human telomeric proteins TRF1 and TRF2 recognize telomeric DNA: a view from high-resolution crystal structures. EMBO Rep 6, 39-45 (2005).

47. $\mathrm{Wu}, \mathrm{X}$. et al. Structural insights into the unique mechanism of transcription activation by Caulobacter crescentus GcrA. Nucleic Acids Res 46, 3245-3256 (2018).

48. Ambrus, A., Chen, D., Dai, J., Jones, R. A. \& Yang, D. Solution structure of the biologically relevant G-quadruplex element in the human c-MYC promoter. Implications for G-quadruplex stabilization. Biochemistry 44, 2048-2058 (2005).

49. Xie, S. et al. Timeless Interacts with PARP-1 to Promote Homologous Recombination Repair. Mol Cell 60, 163-176 (2015).

50. Cortone, G. et al. Interaction of the Warsaw breakage syndrome DNA helicase DDX11 with the replication fork-protection factor Timeless promotes sister chromatid cohesion. PLoS Genet 14, e1007622 (2018).

51. Abe, T. et al. Warsaw breakage syndrome DDX11 helicase acts jointly with RAD17 in the repair of bulky lesions and replication through abasic sites. Proc Natl Acad Sci US A 115, 8412-8417 (2018).

52. Rodriguez, R. et al. A novel small molecule that alters shelterin integrity and triggers a DNA-damage response at telomeres. J Am Chem Soc 130, 15758-15759 (2008).

53. Papadopoulou, C., Guilbaud, G., Schiavone, D. \& Sale, J. E. Nucleotide Pool Depletion Induces G-Quadruplex-Dependent Perturbation of Gene Expression. Cell Rep 13, 24912503 (2015).

54. Gambus, A. et al. GINS maintains association of Cdc45 with MCM in replisome progression complexes at eukaryotic DNA replication forks. Nat Cell Biol 8, 358-366 (2006).

55. Liu, G. et al. Altered Replication in Human Cells Promotes DMPK (CTG)n.(CAG)n Repeat Instability. Molecular and Cellular Biology 32, 1618-1632 (2012).

56. Young, L. M. et al. TIMELESS Forms a Complex with PARP1 Distinct from Its Complex with TIPIN and Plays a Role in the DNA Damage Response. Cell Rep 13, 451-459 (2015).

57. Soldatenkov, V. A., Vetcher, A. A., Duka, T. \& Ladame, S. First evidence of a functional interaction between DNA quadruplexes and poly(ADP-ribose) polymerase-1. ACS Chem Biol 3, 214-219 (2008).

58. Sparks, J. L. et al. The CMG Helicase Bypasses DNA-Protein Cross-Links to Facilitate Their Repair. Cell 176, 167-181.e21 (2019).

59. Simpson, L. J. \& Sale, J. E. Rev1 is essential for DNA damage tolerance and nontemplated immunoglobulin gene mutation in a vertebrate cell line. EMBO J 22, 16541664 (2003).

60. Zhang, Y. et al. Inducible site-directed recombination in mouse embryonic stem cells. Nucleic Acids Res 24, 543-548 (1996).

61. Ross, A. L., Simpson, L. J. \& Sale, J. E. Vertebrate DNA damage tolerance requires the C-terminus but not BRCT or transferase domains of REV1. Nucleic Acids Res 33, 1280-1289 (2005).

62. Ran, F. A. et al. Genome engineering using the CRISPR-Cas9 system. Nat Protoc 8, 2281-2308 (2013).

63. Holzer, S. et al. Crystal structure of the N-terminal domain of human Timeless and its interaction with Tipin. Nucleic Acids Res 45, 5555-5563 (2017).

64. Peränen, J., Rikkonen, M., Hyvönen, M. \& Kääriäinen, L. T7 vectors with modified T7lac promoter for expression of proteins in Escherichia coli. Anal Biochem 236, 371373 (1996). 
65. Kabsch, W. XDS. Acta Crystallographica Section D Biological Crystallography 66, 125-132 (2010).

66. Zwart, P. H. et al. Automated structure solution with the PHENIX suite. Methods Mol Biol 426, 419-435 (2008).

67. McCoy, A. J. et al. Phaser crystallographic software. J Appl Crystallogr 40, 658-674 (2007).

68. Emsley, P. \& Cowtan, K. Coot: model-building tools for molecular graphics. Acta Crystallogr D Biol Crystallogr 60, 2126-2132 (2004).

69. Pettersen, E. F. et al. UCSF Chimera--a visualization system for exploratory research and analysis. J Comput Chem 25, 1605-1612 (2004).

70. Cavanagh, J., Fairbrother, W. J., Palmer, A. G., Rance, M. \& Skelton, N. J. Protein NMR Spectroscopy 2nd Edn. (Academic Press, 2006).

71. Vranken, W. F. et al. The CCPN data model for NMR spectroscopy: development of a software pipeline. Proteins 59, 687-696 (2005).

72. Shen, Y., Delaglio, F., Cornilescu, G. \& Bax, A. TALOS+: a hybrid method for predicting protein backbone torsion angles from NMR chemical shifts. J Biomol NMR 44, 213-223 (2009).

73. Linge, J. P., Habeck, M., Rieping, W. \& Nilges, M. ARIA: automated NOE assignment and NMR structure calculation. Bioinformatics 19, (2003).

74. Brünger, A. T. et al. Crystallography \& NMR system: A new software suite for macromolecular structure determination. Acta Crystallogr D Biol Crystallogr (1998).

75. Langmead, B. \& Salzberg, S. L. Fast gapped-read alignment with Bowtie 2. Nat Methods 9, 357-359 (2012).

76. Li, B. \& Dewey, C. N. RSEM: accurate transcript quantification from RNA-Seq data with or without a reference genome. BMC Bioinformatics 12, 323 (2011).

77. Leng, N. et al. EBSeq: an empirical Bayes hierarchical model for inference in RNA-seq experiments. Bioinformatics 29, 1035-1043 (2013).

78. Quinlan, A. R. \& Hall, I. M. BEDTools: a flexible suite of utilities for comparing genomic features. Bioinformatics 26, 841-842 (2010).

79. Huppert, J. L. \& Balasubramanian, S. Prevalence of quadruplexes in the human genome. Nucleic Acids Res 33, 2908-2916 (2005). 
bioRxiv preprint doi: https://doi.org/10.1101/826578; this version posted October 31, 2019. The copyright holder for this preprint (which was not certified by peer review) is the author/funder, who has granted bioRxiv a license to display the preprint in perpetuity. It is made available under aCC-BY-NC-ND 4.0 International license.

\section{Lerner, Holzer et al. Figure 1}

a

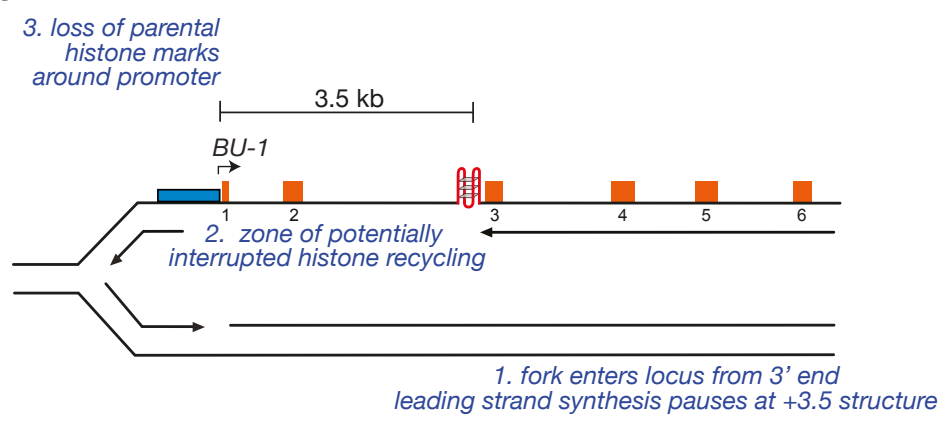

C

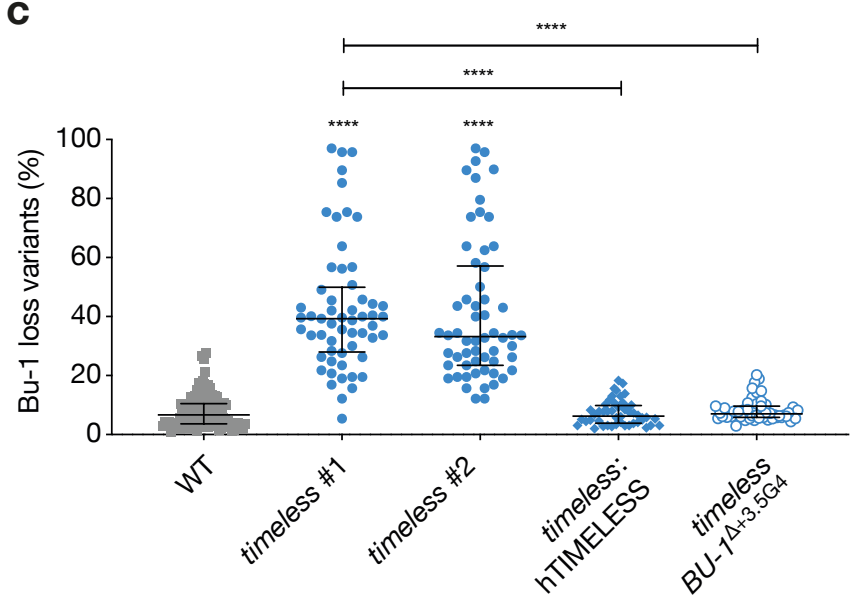

b

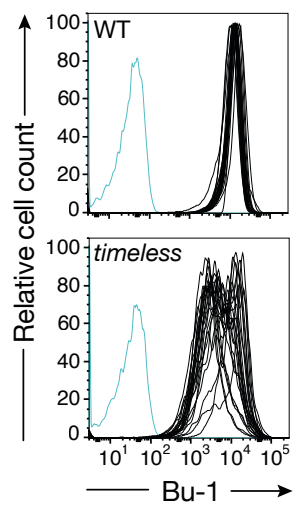

d

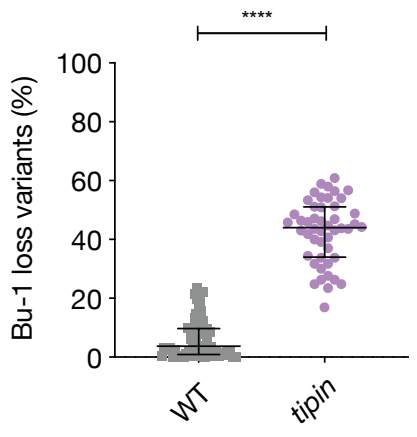


bioRxiv preprint doi: https://doi.org/10.1101/826578; this version posted October 31, 2019. The copyright holder for this preprint (which was not certified by peer review) is the author/funder, who has granted bioRxiv a license to display the preprint in perpetuity. It is made available under aCC-BY-NC-ND 4.0 International license.

\section{Lerner, Holzer et al. Figure 2}

a

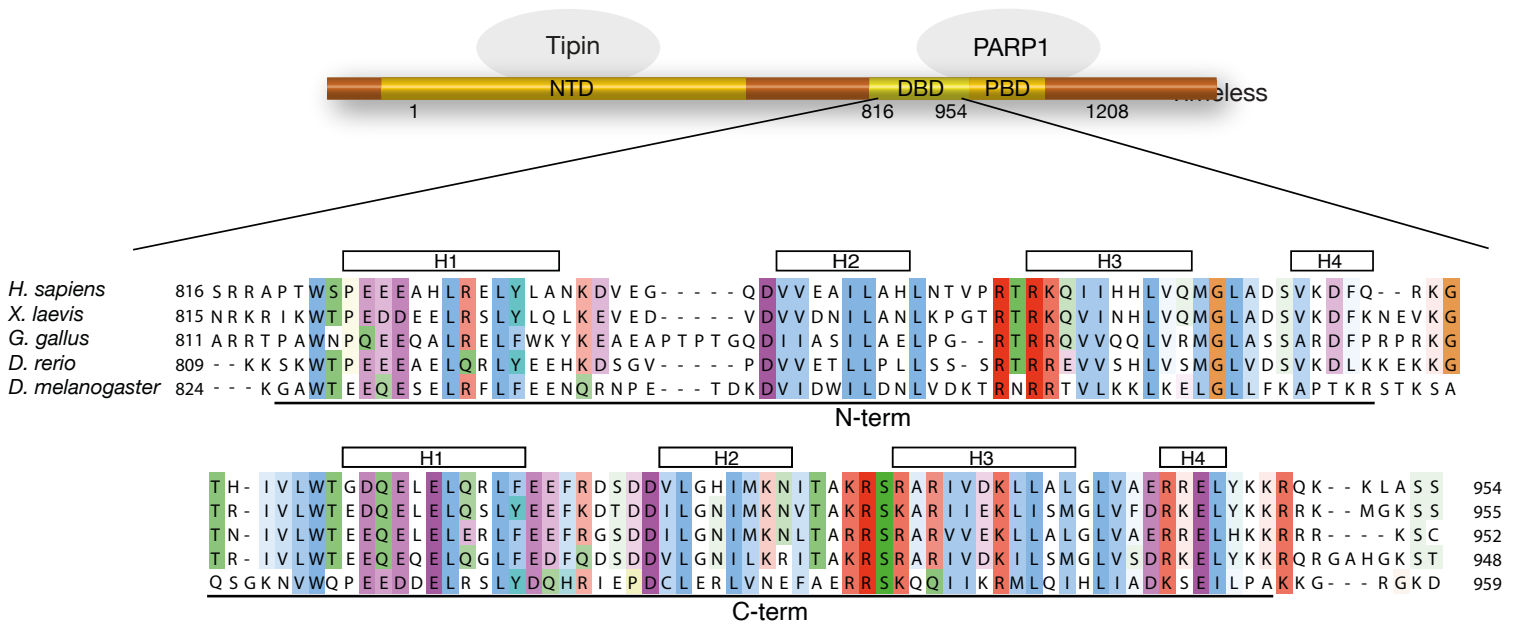

b

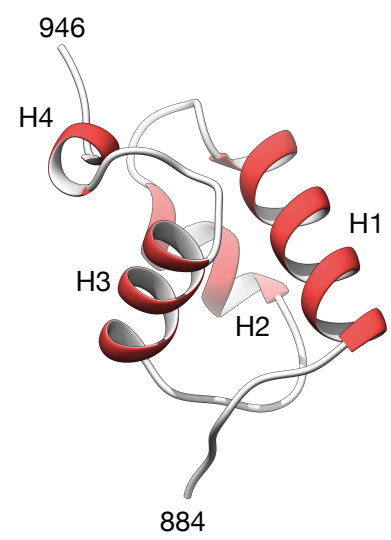

C

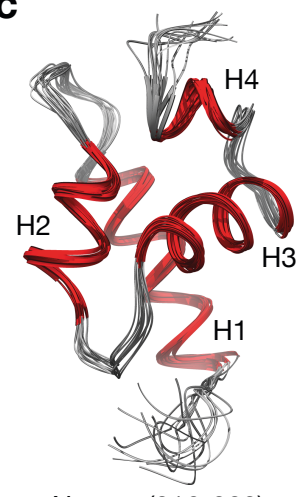

N-term (816-883)

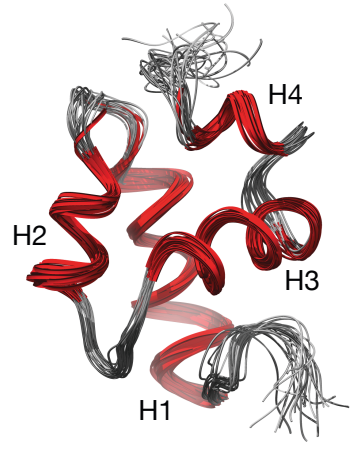

C-term (883-949) d
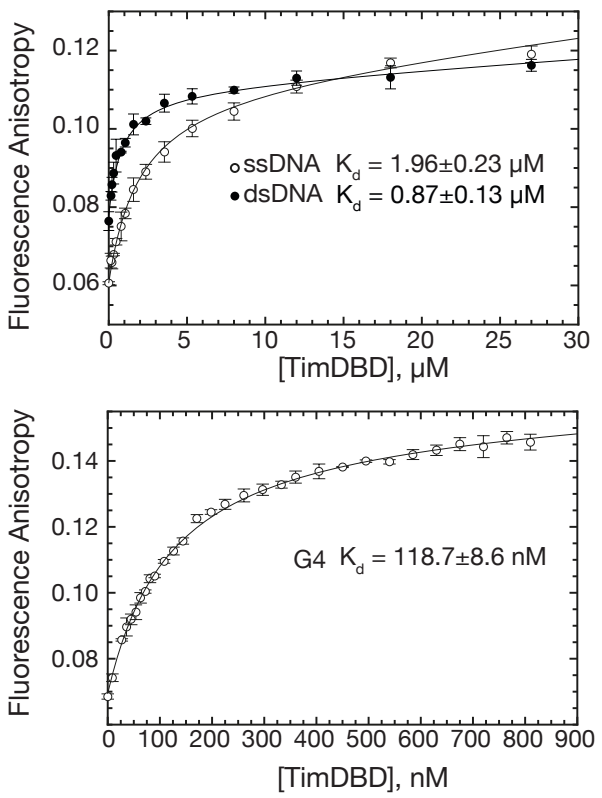

[TimDBD], nM

e

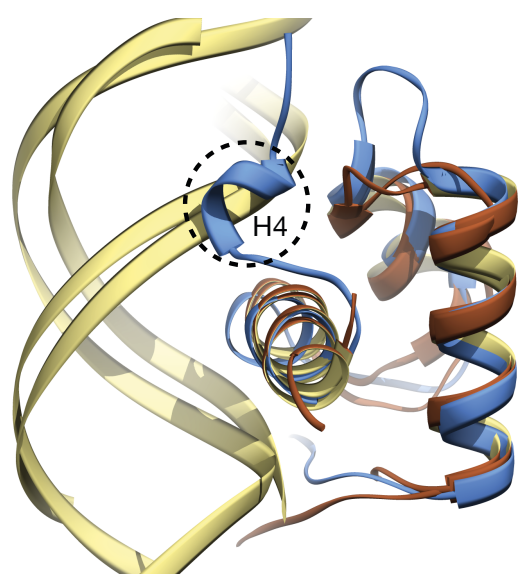


bioRxiv preprint doi: https://doi.org/10.1101/826578; this version posted October 31, 2019. The copyright holder for this preprint (which was not certified by peer review) is the author/funder, who has granted bioRxiv a license to display the preprint in perpetuity. It is made available under aCC-BY-NC-ND 4.0 International license.

\section{Lerner, Holzer et al. Figure 3}

a
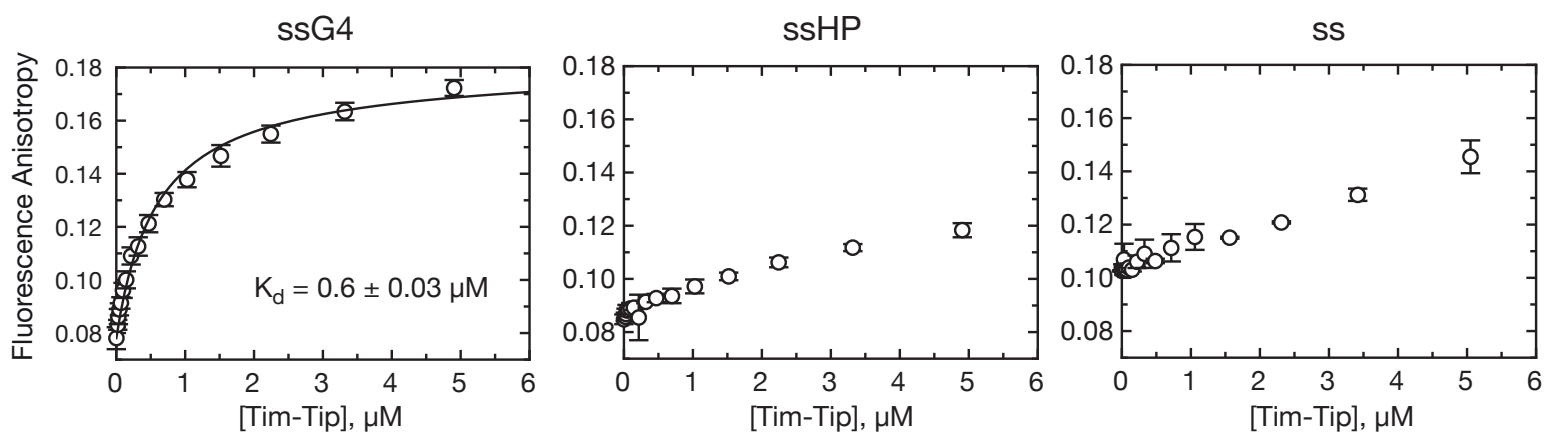

b

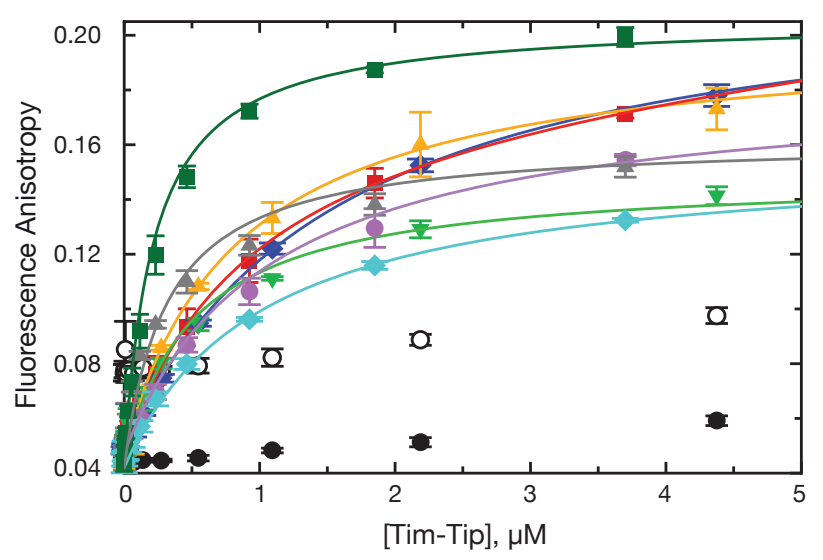

- ssDNA

O dsDNA

- 1XAV

- 2jpz

-203M

$\nabla$ bcl2Mid

- G4_2

- G4_4

- $\rho$-globin

- $B U-1+3.5 \mathrm{G} 4$ 
bioRxiv preprint doi: https://doi.org/10.1101/826578; this version posted October 31, 2019. The copyright holder for this preprint (which was not certified by peer review) is the author/funder, who has granted bioRxiv a license to display the preprint in perpetuity. It is made available under aCC-BY-NC-ND 4.0 International license.

\section{Lerner, Holzer et al. Figure 4}

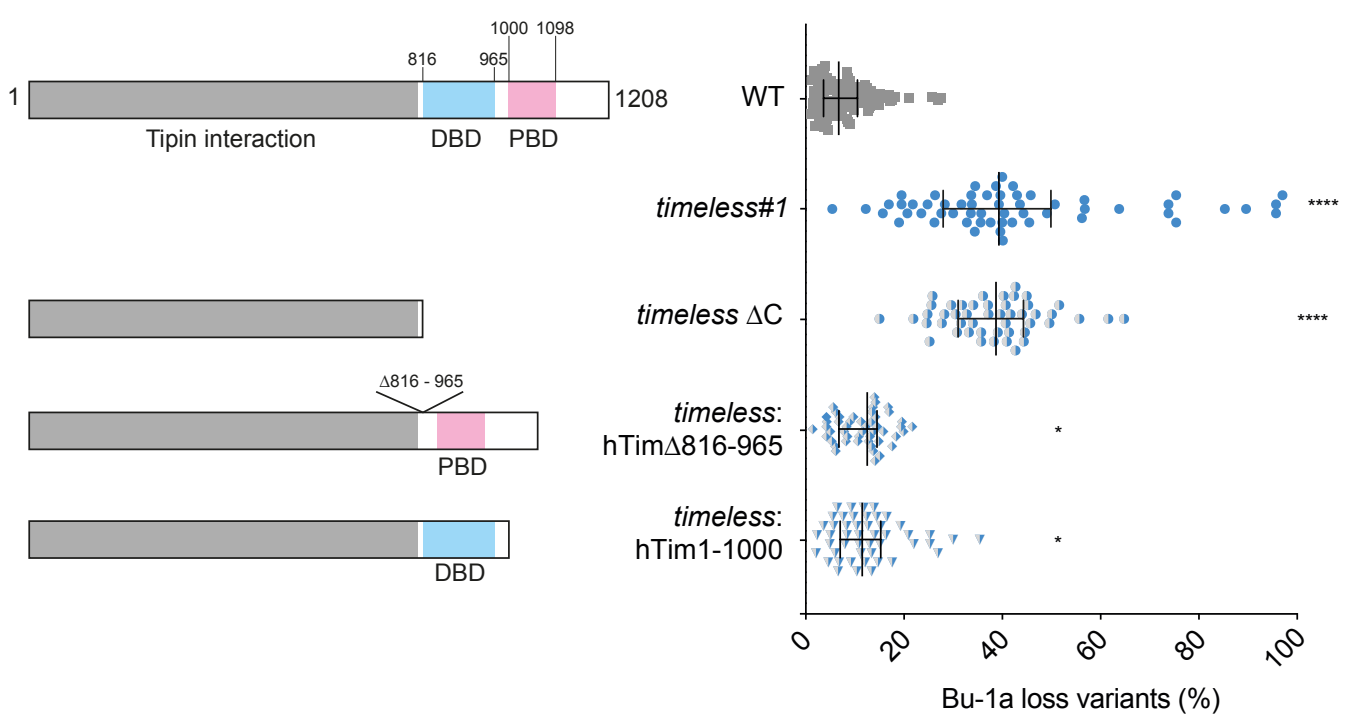


bioRxiv preprint doi: https://doi.org/10.1101/826578; this version posted October 31, 2019. The copyright holder for this preprint (which was not certified by peer review) is the author/funder, who has granted bioRxiv a license to display the preprint in perpetuity. It is made available under aCC-BY-NC-ND 4.0 International license.

a

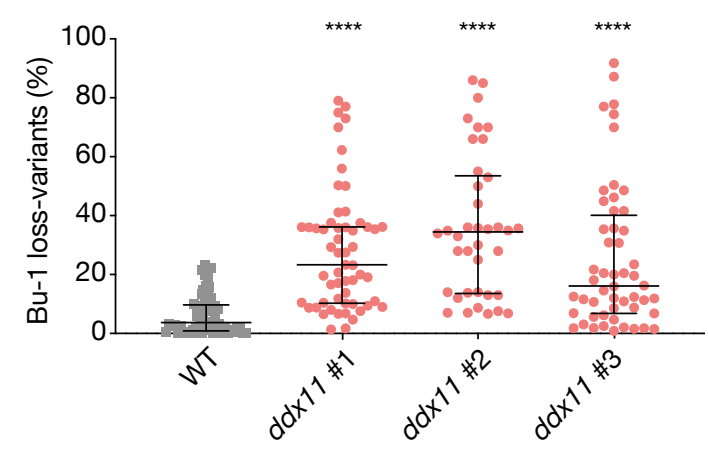

b

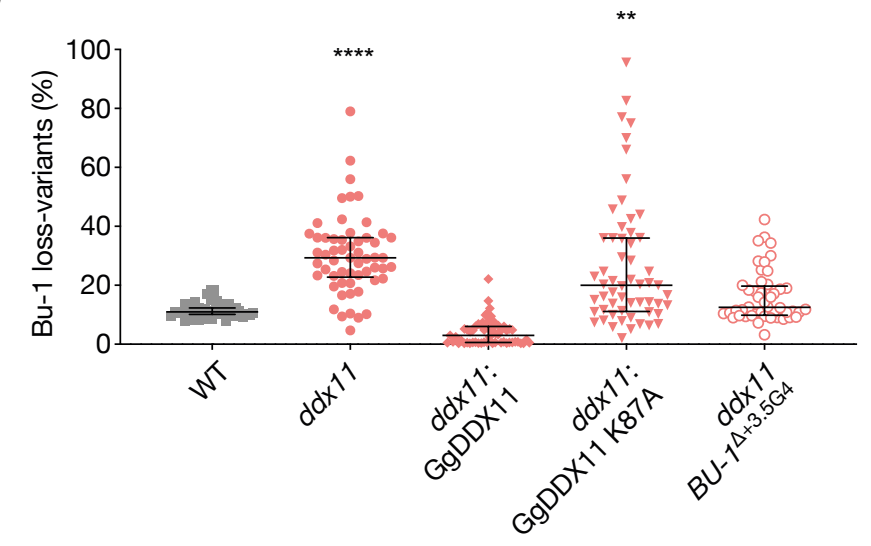

C

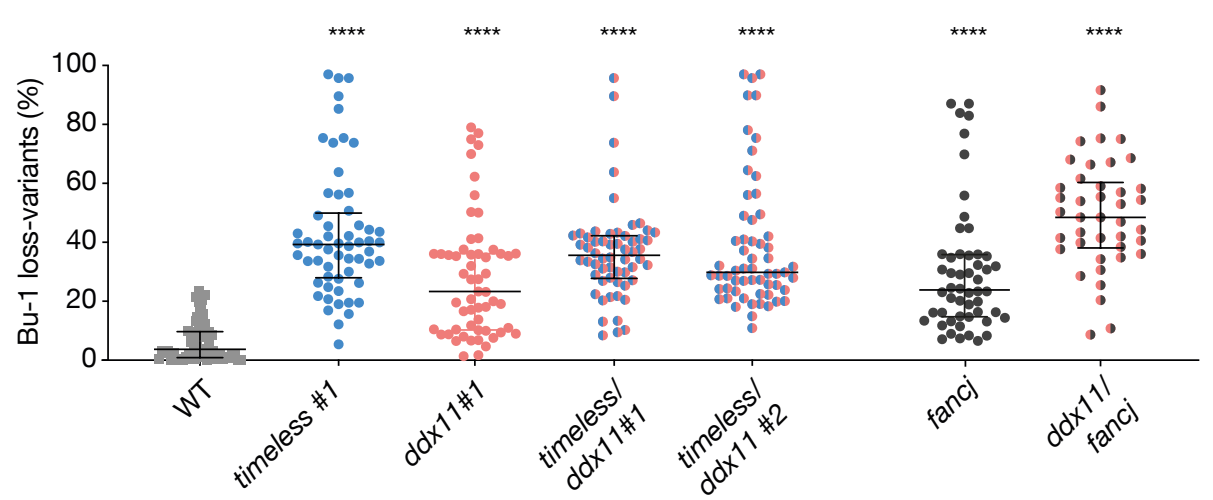


bioRxiv preprint doi: https://doi.org/10.1101/826578; this version posted October 31, 2019. The copyright holder for this preprint (which was not certified by peer review) is the author/funder, who has granted bioRxiv a license to display the preprint in perpetuity. It is made available under aCC-BY-NC-ND 4.0 International license.

a
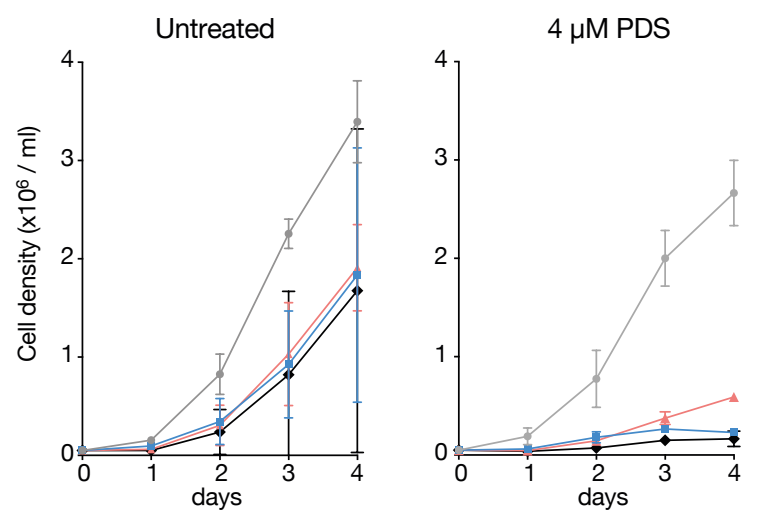

$\rightarrow$ WT

- timeless

$\mp d d \times 11$

- timeless/ddx11

b

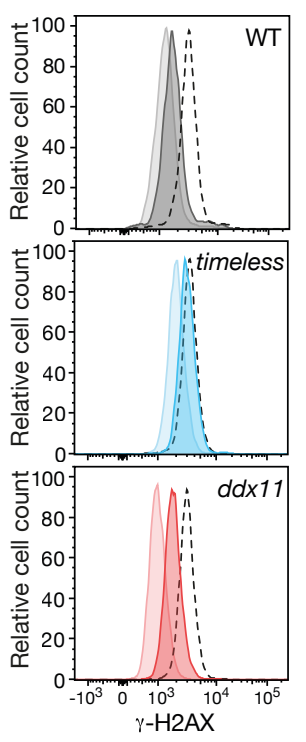

C

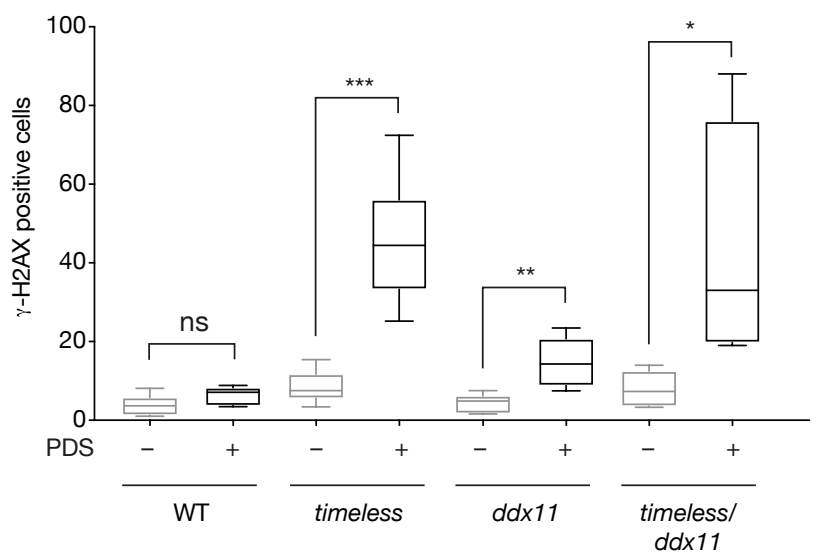


bioRxiv preprint doi: https://doi.org/10.1101/826578; this version posted October 31, 2019. The copyright holder for this preprint (which was not certified by peer review) is the author/funder, who has granted bioRxiv a license to display the preprint in perpetuity. It is made available under aCC-BY-NC-ND 4.0 International license.

a

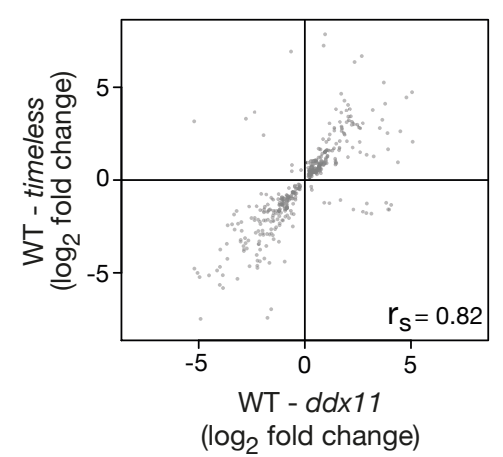

d

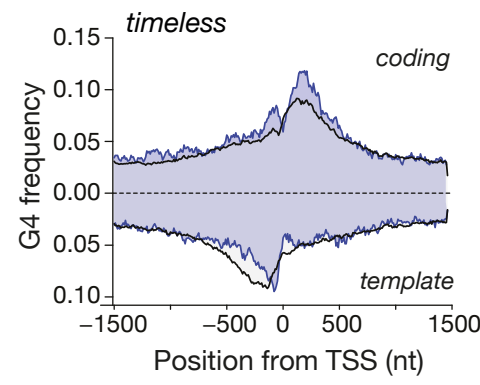

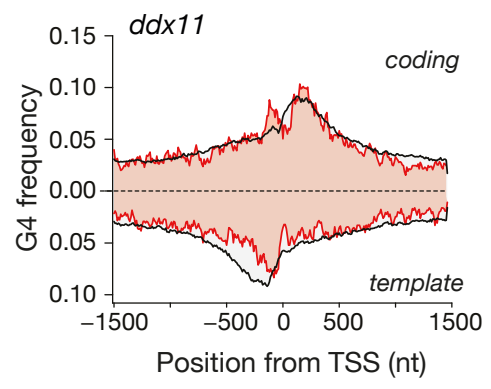

\section{b}

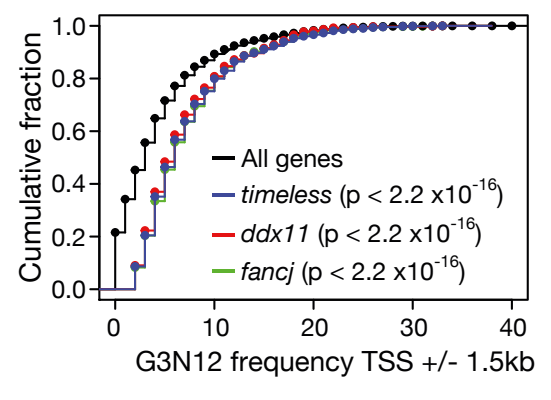

Position from TSS (nt)
C
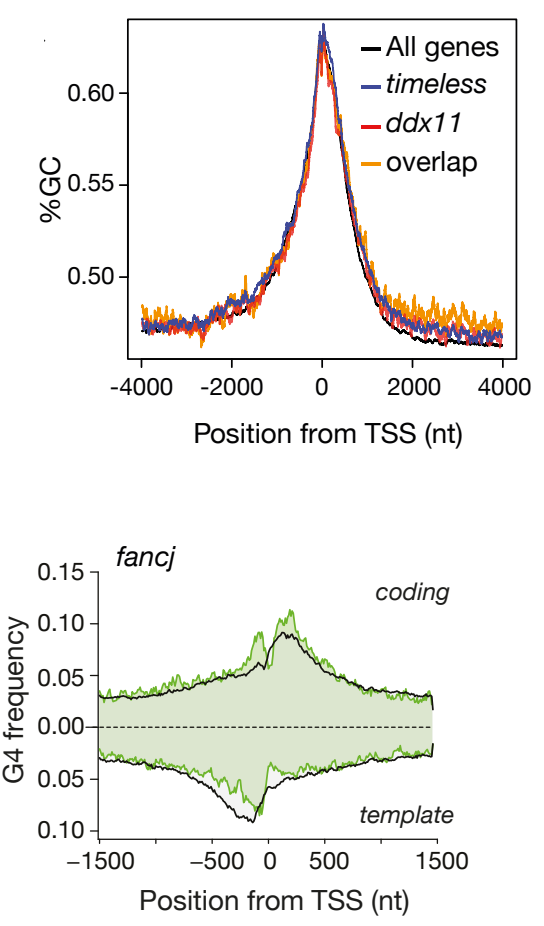

ding

然

e

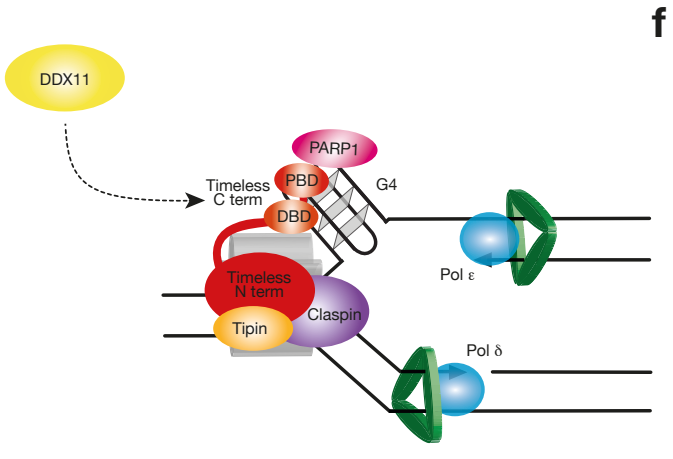

\section{Lerner, Holzer et al. Figure 7}

